\title{
Integration of Mobile Health Into Sickle Cell Disease Care to Increase Hydroxyurea Utilization: Protocol for an Efficacy and Implementation Study
}

Jane S Hankins ${ }^{1 *}, \mathrm{MD}, \mathrm{MS}^{\ddagger}$; Nirmish Shah ${ }^{2 *}, \mathrm{MD}$; Lisa DiMartino ${ }^{3}, \mathrm{PhD}, \mathrm{MPH}$; Donald Brambilla ${ }^{3}$, PhD; Maria E Fernandez ${ }^{4}, \mathrm{PhD}$; Robert W Gibson ${ }^{5}, \mathrm{PhD}$; Victor R Gordeuk ${ }^{6}$, MD; Richard Lottenberg ${ }^{7}$, MD; Abdullah Kutlar ${ }^{5}$, MD; Cathy Melvin ${ }^{8}$, PhD; Jena Simon ${ }^{9}$, MS, APRN; Ted Wun ${ }^{10}$, MD; Marsha Treadwell ${ }^{11}$, PhD; Cecelia Calhoun ${ }^{12}$, MD; Ana Baumann ${ }^{12}$, PhD; Michael B Potter ${ }^{13}$, PhD; Lisa Klesges ${ }^{12}, \mathrm{PhD}$; Hayden Bosworth ${ }^{2}$, PhD; Sickle Cell Disease Implementation Consortium ${ }^{14^{*}}$

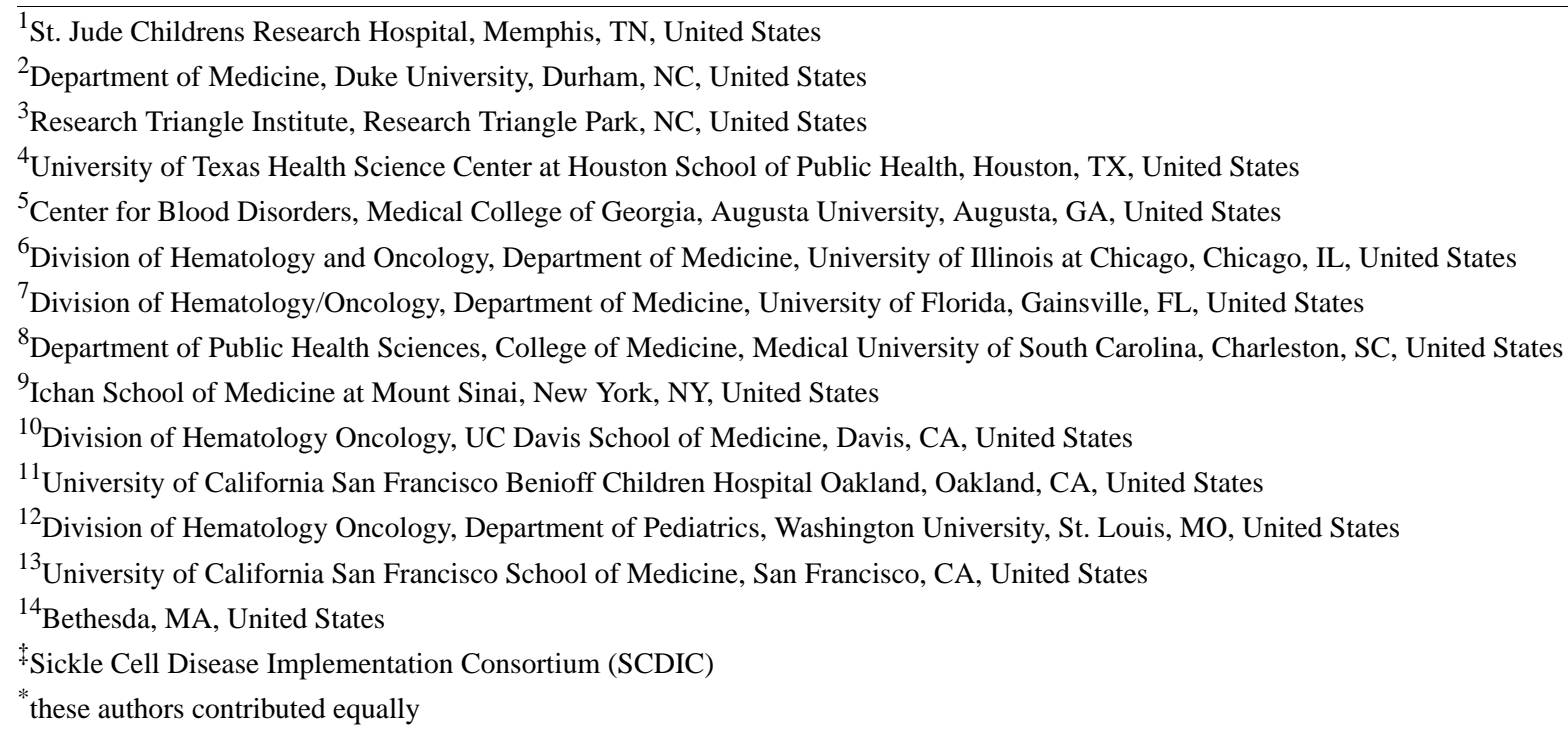

\section{Corresponding Author:}

Jane S Hankins, MD, MS

St. Jude Childrens Research Hospital

262 Danny Thomas place

MS 800

Memphis, TN, 38105

United States

Phone: 19015954153

Email: jane.hankins@stjude.org

\section{Abstract}

Background: Hydroxyurea prevents disease complications among patients with sickle cell disease (SCD). Although its efficacy has been endorsed by the National Health Lung and Blood Institute evidence-based guidelines, its adoption is low, both by patients with SCD and providers. Mobile health (mHealth) apps provide benefits in improving medication adherence and self-efficacy among patients with chronic diseases and have facilitated prescription among medical providers. However, mHealth has not been systematically tested as a tool to increase hydroxyurea adherence nor has the combination of mHealth been assessed at both patient and provider levels to increase hydroxyurea utilization.

Objective: This study aims to increase hydroxyurea utilization through a combined two-level mHealth intervention for both patients with SCD and their providers with the goals of increasing adherence to hydroxyurea among patients and improve hydroxyurea prescribing behavior among providers. 
Methods: We will test the efficacy of 2 mHealth interventions to increase both patient and provider utilization and knowledge of hydroxyurea in 8 clinical sites of the NHLBI-funded Sickle Cell Disease Implementation Consortium (SCDIC). The patient mHealth intervention, InCharge Health, includes multiple components that address memory, motivation, and knowledge barriers to hydroxyurea use. The provider mHealth intervention, Hydroxyurea Toolbox (HU Toolbox), addresses the clinical knowledge barriers in prescribing and monitoring hydroxyurea. The primary hypothesis is that among adolescents and adults with SCD, adherence to hydroxyurea, as measured by the proportion of days covered (the ratio of the number of days the patient is covered by the medication to the number of days in the treatment period), will increase by at least $20 \%$ after 24 weeks of receiving the InCharge Health app, compared with their adherence at baseline. As secondary objectives, we will (1) examine the change in health-related quality of life, acute disease complications, perceived health literacy, and perceived self-efficacy in taking hydroxyurea among patients who use InCharge Health and (2) examine potential increases in the awareness of hydroxyurea benefits and risks, appropriate prescribing, and perceived self-efficacy to correctly administer hydroxyurea therapy among SCD providers between baseline and 9 months of using the HU Toolbox app. We will measure the reach, adoption, implementation, and maintenance of both the InCharge Health and the HU Toolbox apps using the reach, effectiveness, adoption, implementation, and maintenance framework and qualitatively evaluate the implementation of both mHealth interventions.

Results: The study is currently enrolling study participants. Recruitment is anticipated to be completed by mid-2021.

Conclusions: If this two-level intervention, that is, the combined use of InCharge Health and HU Toolbox apps, demonstrates efficacy in increasing adherence to hydroxyurea and prescribing behavior in patients with SCD and their providers, respectively, both apps will be offered to other institutions outside the SCDIC through a future large-scale implementation-effectiveness study.

Trial Registration: ClinicalTrials.gov NCT04080167; https://clinicaltrials.gov/ct2/show/NCT04080167

International Registered Report Identifier (IRRID): DERR1-10.2196/16319

(JMIR Res Protoc 2020;9(7):e16319) doi: 10.2196/16319

\section{KEYWORDS}

sickle cell anemia; digital medicine; adherence; hydroxycarbamide; RE-AIM; implementation science; health innovation; mobile phone

\section{Introduction}

\section{Sickle Cell Disease and Hydroxyurea Therapy}

Sickle cell disease (SCD) is a genetic disorder affecting approximately 100,000 Americans [1]. The effects of SCD are devastating, including severe acute and chronic pain, cognitive disability, renal failure, and lung disease. In controlled clinical trials, hydroxyurea reduces SCD complications (acute pain and acute chest syndrome events) and costs [2-5]. In uncontrolled population studies, hydroxyurea reduces hospitalizations and mortality, supporting the effectiveness of hydroxyurea outside of research studies [6-11]. Hydroxyurea is prescribed in a once-daily dosing, and blood counts are monitored every 1 to 3 months and titrated to reach a maximum tolerated dose defined by mild, reversible myelosuppression [12]. Given the evidence of its benefit, in 2014, the National Institutes of Health/National Heart, Lung, and Blood Institute (NHLBI) released guidelines recommending the use of hydroxyurea [13].

\section{Hydroxyurea Underutilization and Efforts to Improve Its Use}

Despite overwhelming evidence of its positive effects, hydroxyurea is vastly underutilized [14,15]. In analyses conducted using Medicaid claims data, fewer than $50 \%$ of adults were ever prescribed or initiated hydroxyurea, and only about $30 \%$ of those who initiated treatment achieved adequate adherence levels [16-19]. Among children, adherence was higher; however, the number of children who were prescribed hydroxyurea was low [20-22]. Barriers to prescribing hydroxyurea include providers' reluctance due to lack of knowledge about the drug and appropriate dosing, low patient acceptance due to insufficient knowledge or misconceptions about risks and benefits, and forgetfulness leading to poor adherence [14,15,20,23-28]. Patient forgetfulness related to daily hydroxyurea use is a common barrier [29] and may be exacerbated by the prevalence of cognitive dysfunction in patients with SCD, including working memory deficits and low motor processing speed [30-32]. Additionally, negative perceptions toward hydroxyurea are strongly associated with lower adherence to this medication [33]. Among prescribers, the anticipation of poor patient adherence dissuades medical providers from prescribing hydroxyurea [19,20,34].

Improved adherence to hydroxyurea achieves higher fetal hemoglobin $(\mathrm{HbF})$ levels (thereby decreasing polymerization of the sickle hemoglobin), fewer hospital admissions, a higher health-related quality of life, and reductions in health care costs, resulting in major improvements in overall clinical outcomes [35,36].

In an effort to address the underutilization of evidence-based recommendations, including that of hydroxyurea, the NHLBI established the Center for Translation Research and Implementation Science in 2014 [37], and in 2016, the NHLBI funded the SCD Implementation Consortium (SCDIC) [38]. The goal of the SCDIC is to support multilevel and multicomponent interventions to address the quality gap in the delivery of evidence-based treatments for patients with SCD between the ages of 15 and 45 years (when the gap in care delivery is the greatest) employing implementation science strategies. The Integration of mHealth into SCD Care to Increase Hydroxyurea Utilization study is one of the planned multicenter studies within the SCDIC that utilizes the implementation 
science framework and evaluation strategies to increase the adaptation and dissemination of evidence-based treatments among individuals with SCD.

\section{Mobile Health Technology and Its Potential for Sickle Cell Disease Care and Hydroxyurea Utilization}

The existing body of research provides support for mHealth interventions to improve treatment adherence across a variety of chronic conditions, including SCD [39-42]. Among patients with SCD, approximately $85 \%$ to $97 \%$ of patients own smartphones [29,43], and some use this technology to monitor pain $[44,45]$.

Preliminary studies suggest that mHealth interventions can specifically be used to improve hydroxyurea adherence. In children with SCD, the use of text message reminders combined with direct-observed therapy (via video recording) and financial incentives for 6 months significantly increased hydroxyurea adherence and hematologic markers [46,47]. In a study of 81 adolescents with SCD who received text messaging to improve hydroxyurea adherence, significant increases in relevant hematological indices $(\mathrm{HbF}$, mean corpuscular volume [MCV], hemoglobin $[\mathrm{Hb}]$ ) and significant reduction of hemolysis markers (absolute reticulocyte count [ARC], bilirubin, and lactate dehydrogenase [LDH]) were observed [43]. Collectively, these findings suggest that hydroxyurea use can be improved with the use of mHealth via improved adherence. A systematic review of mHealth apps for SCD has confirmed these findings but observed that the sample size of most studies was not large, and the studies were mostly observational or retrospective [42].

mHealth is also increasingly used to aid physicians in their medical decision making [48] and to facilitate consultations with other providers and experts in their areas of expertise [49,50], highlighting the broad applicability of mHealth, not only for patients but also for medical providers. In a survey of health care providers, more than $70 \%$ of physicians had smartphones, and $77 \%$ of nurses and doctors used medical apps [51]. The ease of access and increasing familiarity with apps has led to a growing focus on developing disease-specific medical apps for health care providers.

\section{Logic Model of Change to Increase Hydroxyurea Utilization}

We conceptualized a logic model that guided the development of mHealth apps to foster hydroxyurea utilization among patients and improve provider prescribing behaviors. This logic model used intervention mapping methods to develop and adapt behavioral models for testing mHealth as an intervention to increase hydroxyurea use. Intervention mapping is a systematic framework for developing, implementing, and adapting theoryand evidence-based interventions [52]. Using the knowledge of barriers to the uptake and adherence to hydroxyurea therapy, we mapped the determinants of hydroxyurea utilization (Figure 1). These determinants are hypothesized to drive the behaviors involved in patients' and providers' use of hydroxyurea and correspond to the barriers of hydroxyurea use that were identified through literature review and the results of a needs assessment within the study participating sites. Importantly, the patient and provider interventions were developed and aimed at the determinants that could affect the behavior involved in taking and prescribing hydroxyurea; the ultimate goal (the behavioral outcome) is to foster greater patient adherence to hydroxyurea (Figure 1). 
Figure 1. Logic model of change to increase hydroxyurea utilization. This logic model maps all barriers identified by literature review and needs assessment analysis, with a focus on the determinants of the behaviors to hydroxyurea use. The intervention addresses the determinants of hydroxyurea use at both the patient and provider levels. If this two-level intervention is successful, hydroxyurea utilization will increase, as reflected by increased hydroxyurea adherence, resulting in improved health-related quality of life and reduction in acute health care utilization.

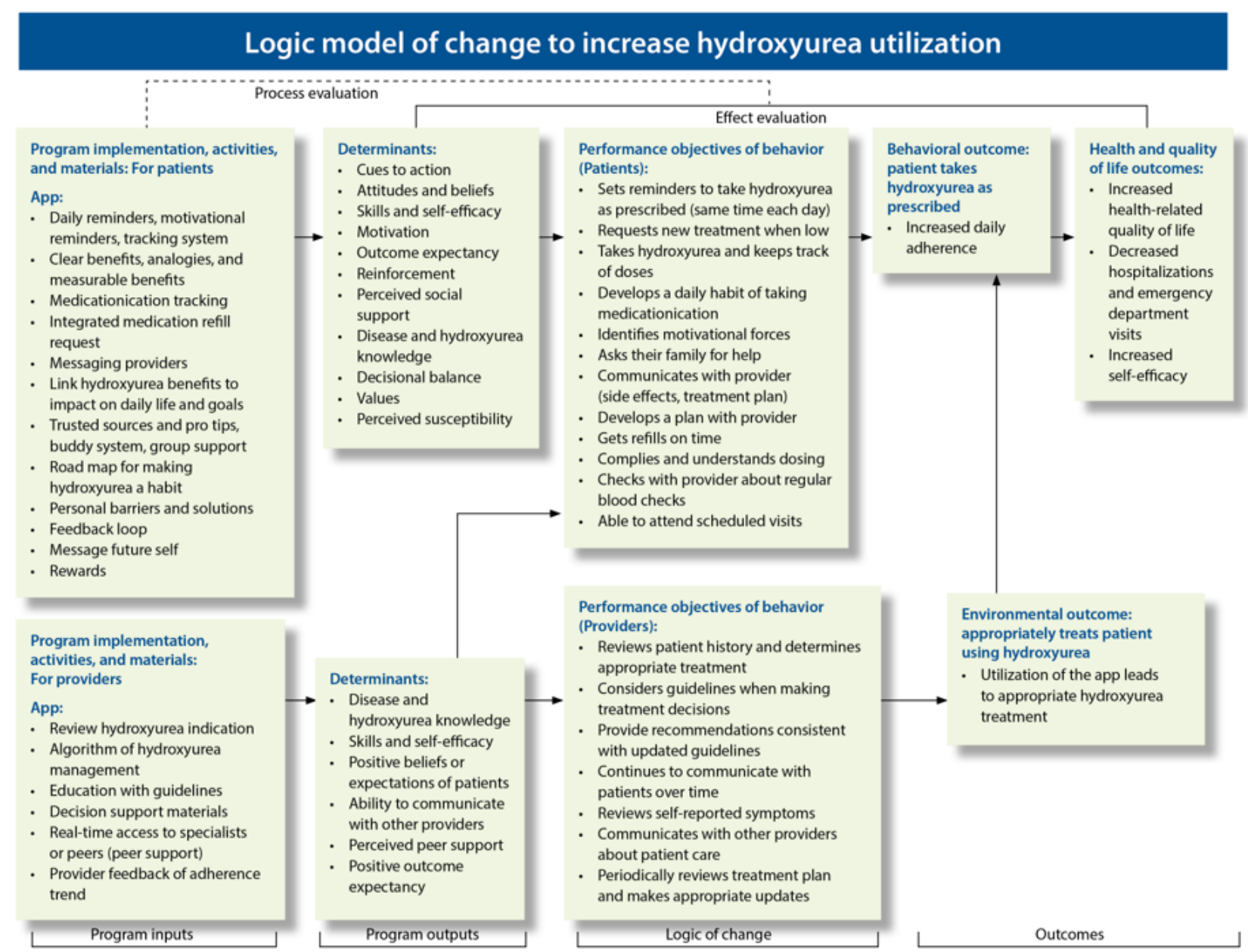

\section{Hydroxyurea Adherence Behaviors for Patients}

To guide the development of the mHealth app for patients, we used the health belief model (HBM) as the framework [53] for behavioral change. The HBM explains health behaviors and focuses on the attitudes and beliefs of individuals. The health-related action driving the increased use of hydroxyurea includes 5 constructs: perceived susceptibility, perceived severity, perceived benefits, perceived barriers, and self-efficacy. Notably, these 5 constructs represent modifiable factors that, together, can influence the increased use of hydroxyurea. The patient intervention focuses on these 5 constructs as the specific mechanisms to address the change in behavior (ie, medication adherence).

\section{Behavioral Model for Mobile Health Utilization Among Medical Providers}

The acceptance of new technology by users, including new mHealth innovations, determines its successful adaptation and, therefore, its intended effects. The perceptions of health care professionals regarding their ability to use mobile health care systems to accomplish a health care task is an important determinant that should also be considered when new technology is implemented. The technology acceptance model $[54,55]$ is a conceptual model that explains the intent to use new information technology (eg, mHealth) or information science among users, including medical providers. Perceived usefulness, perceived ease of use, compatibility, and mobile health care systems self-efficacy are the most important determinants of the behavior intent of providers [56]. We considered all of these drivers and assessed them in the context of the hydroxyurea prescriber to develop the provider HU Toolbox as follows:

- Perceived usefulness: SCD providers require concise information to support clinical decision making while prescribing hydroxyurea.

- Compatibility: The previous experience SCD providers have in using mobile technology was considered.

- Perceived ease of use: The perception of SCD providers that mobile technology can be integrated with their electronic health system and their daily clinical routine.

- Mobile health care systems self-efficacy: SCD providers' perception that mHealth could help with the task of prescribing hydroxyurea. 


\section{Description of the Mobile Health Interventions}

\section{InCharge Health Mobile App}

InCharge Health was developed using a user-centered design approach, in which the patients' input in its development was obtained through an iterative process that started with a design-thinking session, followed by surveys and interviews that investigated barriers and facilitators of hydroxyurea use and preferences for its use [57]. A prototype was developed and further refined using information derived from focus groups with patients with SCD.

The InCharge Health mobile app includes several features to increase patient engagement, including the following: (1) daily customizable text message reminders that can be sent if the patient is hospitalized, (2) a daily recording of hydroxyurea adherence and pain score, (3) a 7-day streak that tracks daily adherence and graphing of adherence against pain symptoms, (4) a communication feature that allows the patient to connect to the health care provider and other patients, and (5) an education bank that provides information about SCD and hydroxyurea risks and benefits in layman's terms (Figure 2). Additionally, InCharge Health has an accountability partner feature that specifies a person (eg, friend, family member) who will receive notifications if the user has not documented the use of hydroxyurea for $>4$ hours (from the time of receipt of the daily reminder) and is encouraged to remind the patient to take their medication. The InCharge Health app does not collect any protected health information and functions in places with Wi-Fi accessibility or using the phone's data plan.

Figure 2. Features of the InCharge Health app for patients. (A) Push notifications will come daily and will prompt the patient participant to mark if the dose was taken, not taken, or be reminded later. (B) Customization of the push notification messages, time of the day, and choice of the accountability partner. (C) A daily pain and mood tracker is available and captures pain level and mood changes. (D) Graphing of pain level versus pain is available for the past 7 days. (E) A link to the patient portal accesses the patient's electronic medical chart, clinic numbers, and patient-led discussion forums. (F) A large resource bank is available with links to vetted educational websites, educational material, and educational videos and is included.

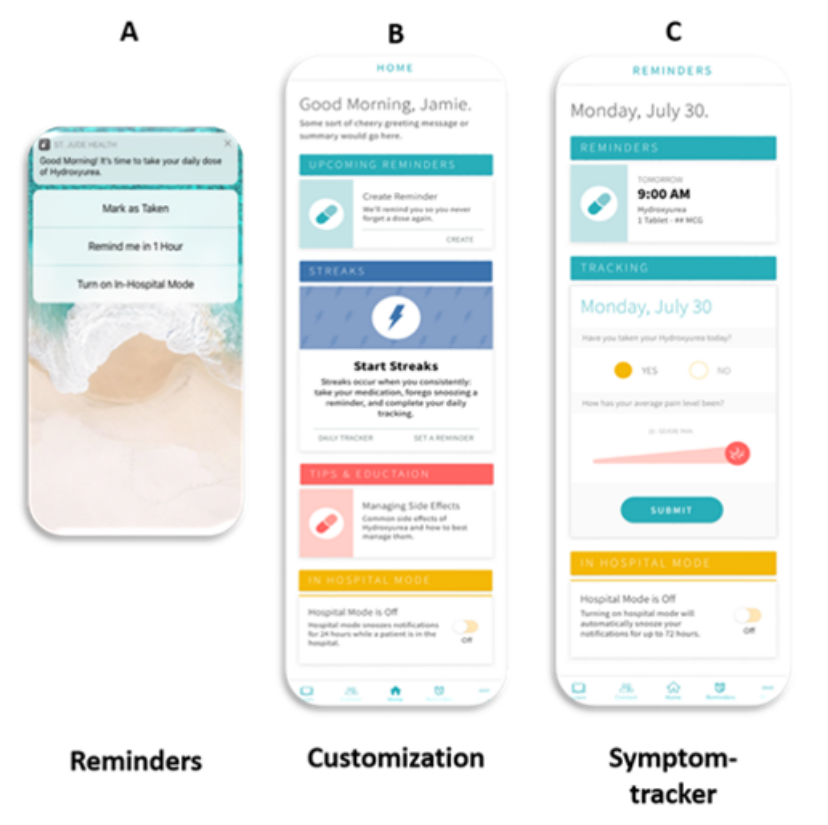

\section{Hydroxyurea Toolbox Mobile App}

The HU Toolbox is a decision-support tool developed with input from pediatricians, internists, and hematologists from several academic centers in North Carolina and members of the Community Care of North Carolina medical home system. The HU Toolbox app contains NHLBI guidelines adapted for pediatric and adult providers (guidelines and recommendations stratified by age). In addition to being an information source,

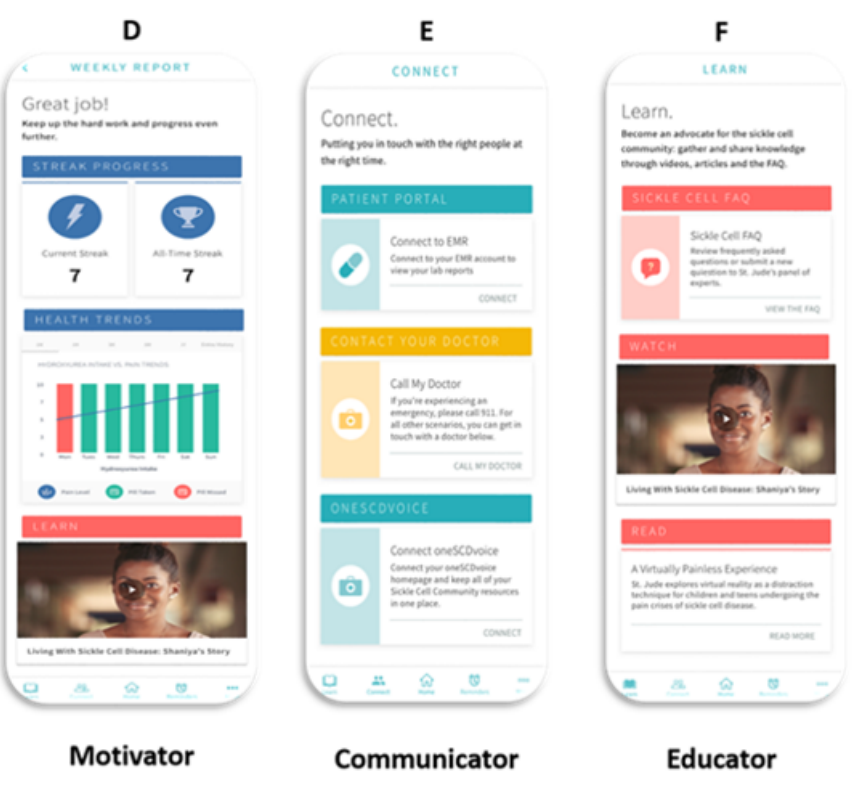

the app contains artificial intelligence algorithms guiding the clinician on how to prescribe hydroxyurea and monitor its effects through a chatbot feature, which simulates a human conversation using text messaging. The HU Toolbox chatbot feature guides clinicians on how to recognize hydroxyurea side effects and how to manage them (Figure 3). Finally, a built-in SCD specialist feature is available, allowing providers to reach and consult SCD experts in their region, who respond to enquiries within 24 hours. 
Figure 3. Features of the HU Toolbox mobile app: The HU Toolbox provides tools for medical providers prescribing hydroxyurea. The app provides a chatbot for users to ask questions about how to dose and monitor hydroxyurea effects and side effects (left panel). In addition, there is educational material available in a library (right panel) as well as the ability to chat directly with a local SCD specialist. HU Toolbox: Hydroxyurea Toolbox; SCD: sickle cell disease.

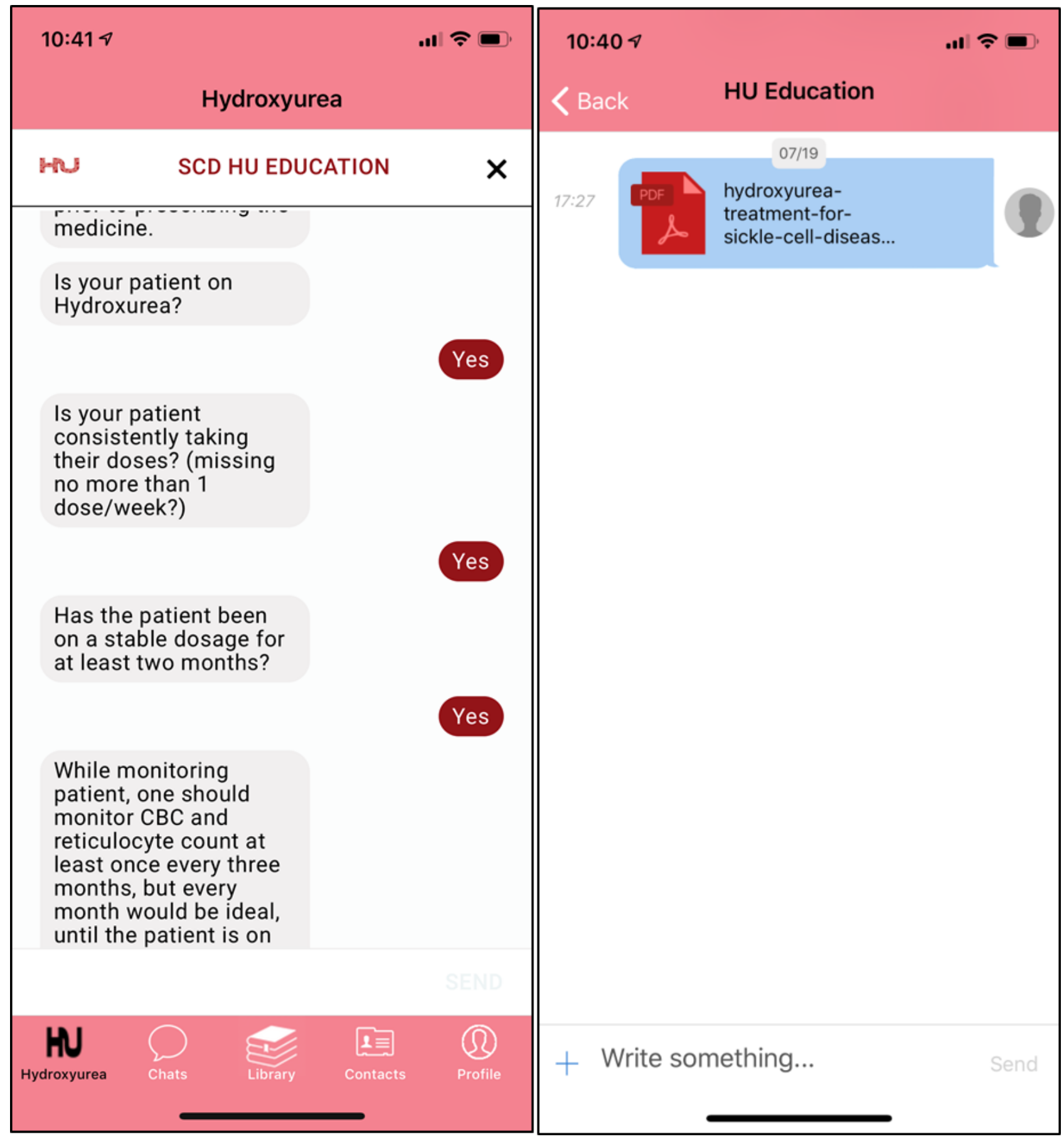

\section{Specific Aims and Objectives}

\section{Aim 1: Improve Patient Adherence to Hydroxyurea}

We will compare adherence to hydroxyurea at baseline with adherence after 6 months of InCharge Health among adolescents and adults with SCD. Our primary hypothesis is that, among patients with SCD, hydroxyurea therapy adherence will increase by $20 \%$ at 24 weeks after receiving the InCharge Health intervention, compared with their hydroxyurea adherence measured at baseline. Adherence will be measured by the proportion of days covered (PDC; the ratio of the number of

days the patient is covered by the medication to the number of days in the treatment period) [58]. The rationale for choosing the primary end point is because a $20 \%$ increase in PDC is a clinically meaningful change and represents an increment of approximately 1.4 additional days of hydroxyurea use in a week's period. Our conservative estimated increase of $20 \%$ refill is based on previous studies that used text messages to increase hydroxyurea adherence and observed adherence increases as high as 60\% [59]. The timing of the primary end point (at 24 weeks) is such that it will allow sufficient time to observe clinical and laboratory changes from increased 
hydroxyurea adherence, as it may take an average of 4 to 6 months to observe full hydroxyurea effects.

\section{Aim 1a: To Assess Patient Engagement and Behaviors Related to Use of InCharge Health}

We will evaluate the consistent use of the app, patient satisfaction, and continued use of the app beyond the study period.

\section{Aim 1b: To Examine the Improvement in Clinical and Patient Outcomes Related to the Use of InCharge Health}

We will investigate changes in the proportion of patients with PDC $>80 \%$, hematologic indices, acute health care utilization, health-related quality of life, and perceived self-efficacy for medication use between baseline and 24 weeks after receiving the InCharge Health intervention.

\section{Aim 2: Improve Provider Hydroxyurea Prescribing Behaviors}

Among providers using the HU Toolbox app, we will examine the changes in knowledge of hydroxyurea benefits and risks as well as perceived self-efficacy to correctly prescribe hydroxyurea therapy between baseline and after 9 months of using the HU Toolbox intervention.

\section{Aim 2a: To Examine Clinical Characteristics and Provider Engagement and Behaviors Related to the Use of the HU Toolbox}

We will evaluate the frequency with which providers use the app and provider satisfaction and continued use of the app beyond the study period.

\section{Aim 2b: To Assess Combined Effects of the Patient and Provider Mobile Health Interventions on Hydroxyurea Adherence and Acute Health Care Utilization.}

We will examine if the changes in hydroxyurea adherence, emergency department visits, and hospitalizations are enhanced by the use of InCharge Health and HU Toolbox concomitantly.

\section{Aim 3}

We will qualitatively evaluate the barriers and facilitators of the implementation of mHealth interventions. We will examine the strategies used to support the implementation of mHealth interventions and evaluate the facilitators and barriers to implementation from multiple stakeholder perspectives: patients, providers, and administrators.

\section{Methods}

The study protocol is reported in accordance with the Standard Protocol Items for Clinical Trials (SPIRIT), where applicable (SPIRIT checklist; Multimedia Appendix 1) [60].

\section{Evaluation Framework}

Key considerations to begin implementing mHealth for hydroxyurea utilization include recruitment in diverse care settings and estimating the reach, effectiveness, adoption, implementation, and maintenance of the apps, which are the 5 components of the RE-AIM framework [61]. RE-AIM is a useful framework to evaluate the utility of mHealth to foster hydroxyurea utilization and to broaden the future applicability and dissemination of the apps [62,63]. RE-AIM will be used in this study to measure the overall impact and robustness of apps to achieve improved patient adherence to hydroxyurea and better prescribing practices of this drug.

\section{Study Design}

The study design is a nonrandomized, closed cohort trial where the 2 mHealth apps will be introduced sequentially in 8 participating clinic sites over 3 time periods (Figure 4). A cohort of subjects recruited from within each site will be followed over each time period in which the unit of analysis will be the patient. Within each site, there will be one or more treatment clinics.

Each provider within a participating clinic will receive the $H U$ Toolbox intervention for 9 months, while each patient participant will receive the InCharge Health app intervention for 6 months. The providers (physicians and advance care practitioners) will begin receiving the provider app 2 months before patients (at the same site) initiate the use of the patient app. There will be a staggered 6 months between groups of sites (Figure 4). The study rollout will allow for a baseline evaluation, followed by preparation and introduction of the provider app (education of providers and remaining staff), followed by implementation of the apps, and evaluation postimplementation (Figure 4). Implementing the interventions at the first 2 sites will allow us to determine any challenges and adapt to ensure increased uptake and implementation for the following sites. 
Figure 4. Study time periods: 2 or 3 groups of sites will enter the study at each of the 3 time periods, and 4 study phases will take place during each study period. T0: introduction of HU Toolbox to providers, provider enrollment, and baseline data collection. T1: introduction of InCharge Health to patients, patient enrollment, and baseline data collection. T2: All enrolled patients and provider participants were followed as active study participants. Each patient will use the InCharge Health app for 6 months, and each provider will use the HU Toolbox app for 9 months. Postintervention data collection: this phase reflects the sustainability of the interventions. We will continue to provide technical support for both patient and provider applications and measure continued utilization of the applications and adherence to hydroxyurea. Solid triangle denotes InCharge Health and HU Toolbox interventions. HU Toolbox: Hydroxyurea Toolbox.

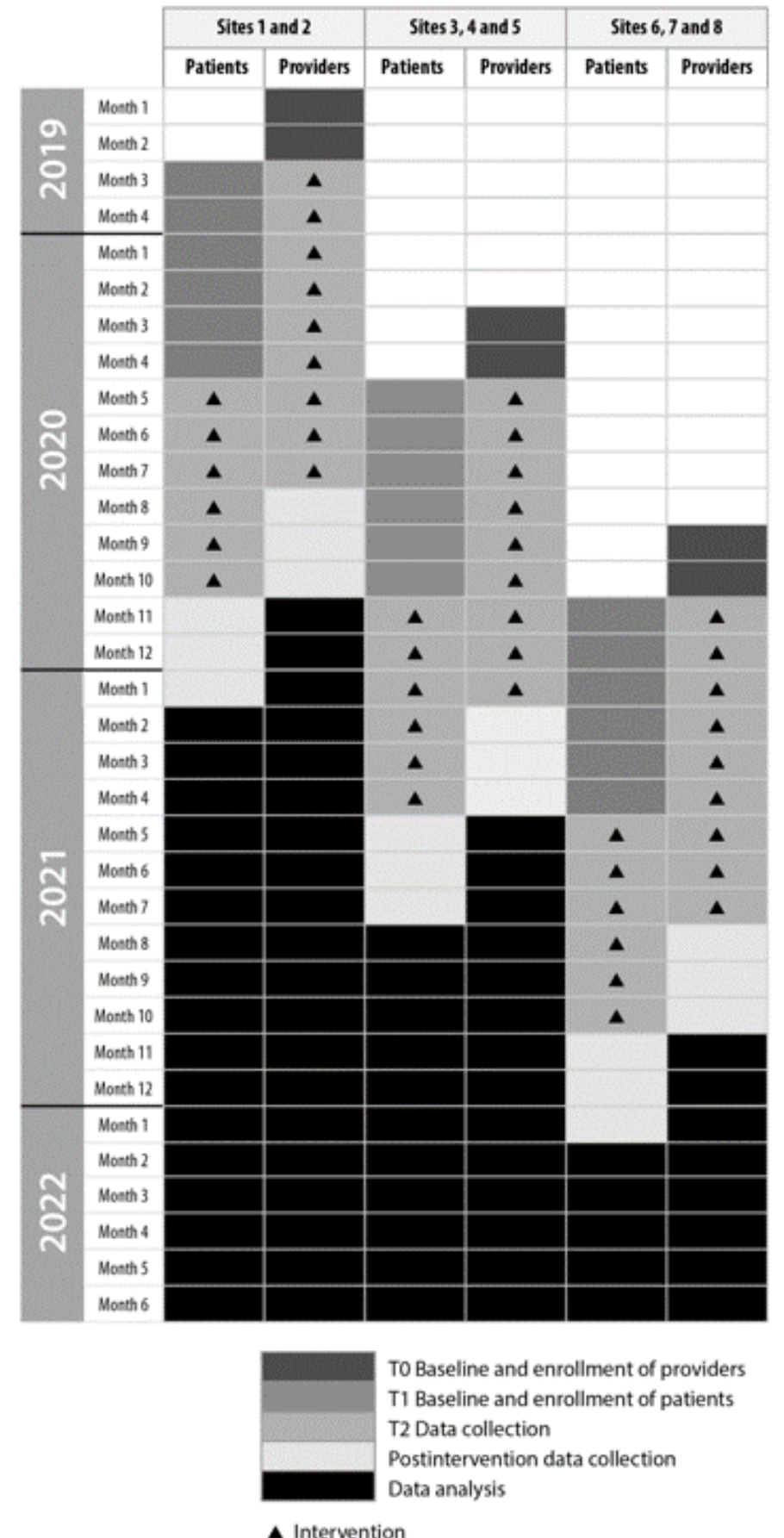

\section{Study Setting}

The study will be carried out at 8 diverse SCDIC participating clinical sites and their subsites. The study settings are variable and include academic and nonacademic sites within urban, suburban, and rural settings. The context for the program is diverse and presents an opportunity to test mHealth in different 
settings, with not only geographical but also structural differences using the RE-AIM evaluation framework.

\section{Participants}

Potential participants will be approached during a nonemergent clinic visit. The study coordinator will verify that the participant (patient or provider) meets the study eligibility criteria (Textboxes 1 and 2), and will approach them in person, phone, or via electronic media about enrolling in the study. Participants will sign an informed consent before study participation (unless a waiver of consent is granted by the local institutional review board). If the participant is a minor, the legal guardian will sign the consent and assent will be obtained. Participants will be considered enrolled when consent is obtained, and inclusion criteria have been confirmed. All providers within each practice will be approached and invited to participate. All clinics will have each provider register within the app to allow provider-specific data. Each site will maintain a local enrollment $\log$ and will also confirm enrollment status in the data management system.

Textbox 1. Inclusion and exclusion criteria for patient participants.

Inclusion criteria

- $\quad$ Between 15 and 45 years

- $\quad$ Treated at or affiliated with one of the sickle cell diseases implementation consortium sites

- $\quad$ English speaking

- $\quad$ Confirmed sickle cell disease diagnosis by a hemoglobin fractionation test

- $\quad$ Owns a cellular/mobile smartphone (either Android or iOS)

- Hydroxyurea therapy:

- Already receiving hydroxyurea therapy (at least one previous prescription for hydroxyurea in the past 3 months) or

- Initiating hydroxyurea therapy (the first prescription must be written on the same day as study enrollment). Patient participants who initiate hydroxyurea on the same day of study enrollment will not contribute to the total target accrual for the site, but rather will be analyzed as a separate group

Exclusion criteria

- Known current pregnancy

- A red blood cell transfusion in the past 60 days. This is necessary as transfusions will mask laboratory markers and clinical changes from hydroxyurea

- Currently using consistency. another cellphone app or a web-based tool (electronic health tool) to increase hydroxyurea adherence

Textbox 2. Inclusion criteria and the exclusion criterion for provider participants.

Inclusion criteria

- Physician (including physician in training) or advanced practice provider (nurse practitioner or physician assistant) who cares for at least one patient with sickle cell disease for an anticipated minimum of 12 months from study enrollment

- Access to a cellular/mobile smartphone (either Android or iOS) or access to a computer with internet connectivity (HU Toolbox app can be accessed via the internet on any device)

- Exclusion criterion

- Currently using another phone app or a web-based tool to increase hydroxyurea adherence for patients with SCD in his/her practice

\section{Implementation Strategies}

To promote the uptake of both the patient and provider mHealth apps into practice, we will employ multiple implementation strategies. Sites will be provided with a list of discrete strategies (eg, education strategies such as conducting ongoing training and regular check-ins with patients and providers regarding app functionality). Each clinical site will be able to select a strategy or strategies that best fit their context. All sites will be required to provide training on the apps for both patients and providers using a standard training protocol, which is detailed in the study standard operating procedure document. Research staff will guide the participants on the installation of InCharge Health and HU toolbox on the participants' mobile devices (or computer in the case of providers). Using a developed script, the research team will provide instructions about app settings, explain how to use the app, and answer any questions. Before participants leave the clinic, patients will be asked to demonstrate their knowledge and ability to use the app. Centralized technical assistance (by the app developers) will be provided for both apps to ensure a high level of fidelity in their implementation. Specifically, patients and providers will be given a number to call and an email address if they have questions regarding the app or the study in general. Data related to technical problems related to the apps will be tracked to evaluate their functionality. 


\section{Study Outcome Measures}

\section{Primary Outcome}

Efficacy will be determined by assessing the impact of InCharge Health on hydroxyurea by measuring the change in PDC from baseline (before intervention) to week 24 (primary outcome). For the PDC, the pharmacy that fills the most prescription claims within the target therapeutic category for a specific patient within the calendar range will be assigned responsibility for the patient. The pharmacy name and number where hydroxyurea is filled will be collected by the research coordinators at each study visit, and refill information will be requested from these pharmacies. All prescription drug refills, from all dispensing pharmacies, will be ascertained.

\section{Secondary Outcomes}

These include daily recorded adherence on the app; proportion of patients with PDC $\geq 80 \%$; laboratory markers of hydroxyurea response $(\mathrm{HbF}, \mathrm{Hb}$ concentration, MCV, ARC, absolute neutrophil count, indirect bilirubin, LDH); health care utilization (hospitalizations and emergency department visits); health-related quality of life; perceived health literacy, patient medication self-efficacy, and implementation outcomes.

\section{Data Collection}

After enrolling, patient participants will return at 12 and 24 weeks for study visits, where study-related procedures will be conducted (Table 1). Provider participants will complete an assessment of self-confidence in prescribing hydroxyurea at baseline and at the study exit (Table 2). Three months after study completion, InCharge Health and HU Toolbox usage will be assessed via analysis of app statistics. Additionally, at study completion, we will solicit feedback from patients and providers regarding the clinical usefulness of the apps and their usability and impact. (Tables 1 and 2). Clinical and implementation measures will be assessed using the RE-AIM framework, both for InCharge Health (Table 3) and HU Toolbox (Table 4).

We will conduct 15 semistructured key-informant interviews (30-60 min) with multiple key stakeholders toward the end of app implementation at each of the study sites. We will purposively sample and interview patients and providers (physicians and advance care practitioners) from each site according to mHealth app use (low uptake vs high uptake). The RE-AIM framework was used to develop the interview guides and systematically assess barriers and facilitators. For example, patients will be asked how using InCharge Health impacts the way they take hydroxyurea, whereas providers will be asked how using the HU Toolbox impacts the way they prescribe hydroxyurea. Patients and providers will also be asked about why they chose to participate in the study, training received for the apps, and whether they would continue to use the apps after the study is complete. We also plan interviews with clinic administrators to gain a clinic-level perspective on factors that influenced implementation. 
Table 1. Schedule of evaluations for patient participants.

\begin{tabular}{lllll}
\hline Measures and definition & $\begin{array}{l}\text { Week 24 (retrospec- } \\
\text { tively collected) }\end{array}$ & $\begin{array}{l}\text { Base- } \\
\text { line }\end{array}$ & $\begin{array}{l}\text { Week } \\
12\end{array}$ & $\begin{array}{l}\text { Week 24 } \\
\text { (study exit) }\end{array}$ \\
\hline
\end{tabular}

Socio d emographic

Age, sex, race, ethnicity, marital status, educational attainment, health in-

surance type, income, occupation

Informed consent

Patient adherence to hydroxyurea (Aim 1) and the combined effects of the patient and provider mHealth ${ }^{\mathrm{c}}$ interventions (Aim $2 \mathrm{~b}$ )

Hydroxyurea adherence

\begin{tabular}{|c|c|c|c|c|}
\hline Proportion of daily coverage & $\mathrm{x}$ & $\mathrm{x}$ & $\mathrm{x}$ & $\mathrm{x}$ \\
\hline App daily adherence statistics and 7-day recall measure using the brief & - & $\mathrm{x}$ & & $\mathrm{x}$ \\
\hline
\end{tabular}

Clinical influence of the InCharge Health app; (Aim 1b) and the combined effects of the patient and provider mHealth interventions (Aim 2b)

\section{Hydroxyurea effect}

Date hydroxyurea initiated

$\operatorname{MTD}^{\mathrm{d}}$ dose $(\mathrm{mg} / \mathrm{kg} /$ day $)$ and date reached

Current dose ( $\mathrm{mg} / \mathrm{kg} /$ day and $\mathrm{mg} /$ day)

Biomarkers of hydroxyurea effect $\left(\mathrm{HbF}^{\mathrm{e}} \%, \mathrm{Hb}^{\mathrm{f}}, \mathrm{MCV}^{\mathrm{g}}, \mathrm{ANC}^{\mathrm{h}}, \mathrm{ARC}^{\mathrm{i}}, \quad \mathrm{x}\right.$ indirect bilirubin, $\mathrm{LDH}^{\mathrm{j}}$ )

\section{Health care utilization}

Date and discharge diagnosis of $\mathrm{ED}^{\mathrm{k}}$ visits, acute care/infusion visit hospi- $\quad \mathrm{x}$ talizations

\section{Self-efficacy and health literacy}

PROMIS $^{1}$ self-efficacy for medication short form

Perceived health literacy

Health-related quality of life and pain report

ASCQ-Me ${ }^{\mathrm{m}}$ pain impact, ASCQ-Me pain episode frequency and severity, PROMIS pain quality

Engagement of patients related to the use of InCharge Health app (Aim 1a)

Implementation measures

See Tables 3 and 4

mHealth satisfaction

Perceived usability and acceptability of mHealth intervention $\left(\right.$ MARS $\left.^{\mathrm{n}}\right)$ [64]

Evaluation of facilitators and barriers to implementation of the mHealth app (Aim 3)

Barriers and facilitators to implementation

Qualitative interviews ${ }^{\mathrm{o}}$

\footnotetext{
${ }^{\mathrm{a}}$ Denotes not done at this timepoint.

${ }^{\mathrm{b}} \mathrm{x}$ denotes done at this timepoint.

${ }^{c}$ mHealth: mobile health.

${ }^{\mathrm{d}}$ MTD: maximum tolerated dose.

${ }^{\mathrm{e}} \mathrm{HbF}$ : fetal hemoglobin.

${ }^{\mathrm{f}} \mathrm{Hb}$ : hemoglobin.

${ }^{\mathrm{g}} \mathrm{MCV}$ : mean corpuscular volume.

${ }^{\mathrm{h}}$ ANC: absolute neutrophil count.

${ }^{\mathrm{i}} \mathrm{ARC}$ : absolute reticulocyte count.
} 
${ }^{\mathrm{j}} \mathrm{LDH}$ : lactate dehydrogenase.

${ }^{k}$ ED: emergency department.

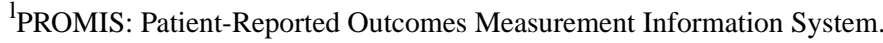

mASCQ-Me: adult sickle cell quality of life measurement information system.

${ }^{\mathrm{n}}$ MARS: mobile app rating scale.

${ }^{\circ}$ Conducted at the end of the study at each site.

Table 2. Schedule of evaluations for provider participants.

\begin{tabular}{|c|c|c|c|}
\hline Measure and definition & Baseline & $\begin{array}{l}\text { Week } 36 \\
\text { (study exit) }\end{array}$ & $\begin{array}{l}\text { Week } 48 \\
\text { (poststudy) }\end{array}$ \\
\hline \multicolumn{4}{|l|}{ Sociodemographic } \\
\hline $\begin{array}{l}\text { Age, sex, race, ethnicity, type of professional (physician, nurse practitioner, physician assistant), } \\
\text { years in practice }\end{array}$ & $\mathrm{x}^{\mathrm{a}}$ & $-^{b}$ & - \\
\hline Informed consent & - & - & - \\
\hline \multicolumn{4}{|l|}{ Improve provider hydroxyurea awareness, prescribing, and monitoring behaviors (Aim 2) } \\
\hline \multicolumn{4}{|l|}{ Self-efficacy and hydroxyurea knowledge } \\
\hline $\begin{array}{l}\text { Perceived confidence in prescribing hydroxyurea to patients with } \mathrm{SCD}^{\mathrm{c}} \text {, including correct daily } \\
\text { dosing }\end{array}$ & $\mathrm{x}$ & $\mathrm{x}$ & - \\
\hline \multicolumn{4}{|l|}{ Engagement of providers related to the use of the HU Toolbox app (Aim 2a) } \\
\hline \multicolumn{4}{|l|}{ Implementation and mHealth satisfaction } \\
\hline Perceived usability and acceptability of mHealth intervention (MARS ${ }^{\mathrm{d}}$ scale) [64] & - & $\mathrm{x}$ & - \\
\hline \multicolumn{4}{|l|}{ Hydroxyurea prescribing practices (clinic-level measures) } \\
\hline Total number of patients with SCD & $\mathrm{x}$ & $\mathrm{x}$ & $\mathrm{x}$ \\
\hline Number of patients eligible to receive hydroxyurea therapy at provider participant's site ${ }^{\mathrm{e}}$ & $\mathrm{x}$ & $\mathrm{x}$ & $\mathrm{x}$ \\
\hline Number of hydroxyurea-eligible patients who are prescribed hydroxyurea (all sickle genotypes) ${ }^{\mathrm{e}}$ & $\mathrm{x}$ & $\mathrm{x}$ & $\mathrm{x}$ \\
\hline \multicolumn{4}{|l|}{ Evaluation of facilitators and barriers to implementation of the mHealth app (Aim 3) } \\
\hline \multicolumn{4}{|l|}{ Barriers and facilitators to implementation } \\
\hline Qualitative interviews ${ }^{\mathrm{f}}$ & - & $\mathrm{x}$ & - \\
\hline
\end{tabular}

${ }^{\mathrm{a}} \mathrm{x}$ denotes done at this time point.

${ }^{\mathrm{b}}$ Denotes not done at this time point.

${ }^{\mathrm{c}} \mathrm{SCD}$ : sickle cell disease.

dMARS: mobile app rating scale.

${ }^{\mathrm{e}}$ Hydroxyurea eligibility will follow the 2014 National Health Lung and Blood Institute guidelines as follows: hydroxyurea should be offered to all children with homozygous sickle hemoglobin mutation (HbSS) and compount heterozygous sickle hemoglobin and null beta thalassemia ( $\mathrm{HbS} \beta^{0}$-thalassemia) age $\geq 9$ months and prescribed to all symptomatic adults with $\mathrm{HbSS} / \mathrm{HbS} \beta^{0}$-thalassemia, that is, $>3$ episodes of severe vaso-occlusion in the preceding 9 months [13].

${ }^{\mathrm{f}}$ Conducted at the end of the study at each site.

For additional information on Implementation and mHealth satisfaction, please refer to Tables 3 and 4 
Table 3. The reach, effectiveness, adoption, implementation, and maintenance evaluation measures of InCharge Health implementation.

\begin{tabular}{|c|c|c|}
\hline Domains and measures & & Data sources \\
\hline Reach & 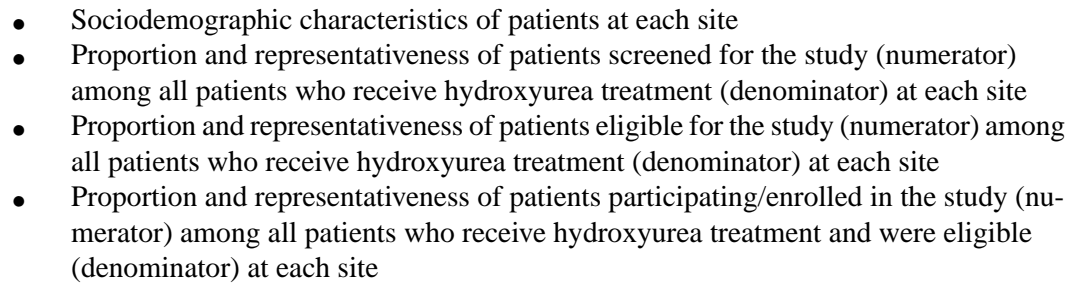 & $\begin{array}{l}\text { - Clinic data collection } \\
\text { forms } \\
\text { Clinic population demo- } \\
\text { graphics and treatment } \\
\text { data, study database } \\
\text { - } \\
\text { - } \\
\text { Qualitative interviews }\end{array}$ \\
\hline \multirow[t]{2}{*}{ Effectiveness } & 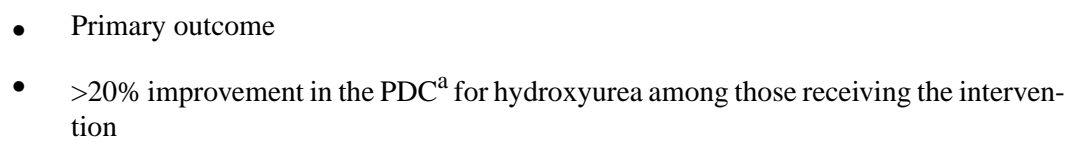 & $\begin{array}{l}\text { Prescription drug } \\
\text { claims (PDC for hy- } \\
\text { droxyurea refills) }\end{array}$ \\
\hline & $\begin{array}{l}\text { - Secondary outcomes } \\
\text { - Change in Quality of life, self-efficacy, perceived health literacy } \\
\text { - Change in percentage of patients with } \mathrm{ED}^{\mathrm{b}} \text { visits, hospitalizations since the last study } \\
\text { visit } \\
\text { - } \quad \text { Change in biomarkers of hydroxyurea effect }\left(\mathrm{MCV}^{\mathrm{c}}, \mathrm{ANC}^{\mathrm{d}}, \mathrm{ARC}^{\mathrm{e}} \text {, indirect bilirubin, }\right. \\
\left.\mathrm{HbF}^{\mathrm{f}}, \mathrm{Hb}^{\mathrm{g}}, \mathrm{LDH}^{\mathrm{h}}\right)\end{array}$ & $\begin{array}{l}\text { Patient surveys (AS- } \\
\text { CQ-Me }{ }^{\mathrm{i}} \text {, PROMIS } \\
\text { Perceived health litera- } \\
\text { cy, self-efficacy) } \\
\text { - Medical chart abstrac- } \\
\text { tion } \\
\text { - Qualitative interviews }\end{array}$ \\
\hline Adoption & $\begin{array}{l}\text { - Proportion and description of clinics in each site agreeing to support InCharge Health } \\
\text { - Proportion and description of providers in each clinic agreeing to support InCharge } \\
\text { Health (ie, proportion enrolled on the study) }\end{array}$ & $\begin{array}{l}\text { - Clinic administrative } \\
\text { data and data collection } \\
\text { forms } \\
\text { - } \quad \text { Qualitative interviews }\end{array}$ \\
\hline Implementation & $\begin{array}{l}\text { - Consistency with which sites are able to implement the app as planned } \\
\text { - } \quad \text { Qualitative assessment of any adaptations or enhancement to recruitment strategies } \\
\text { needed to meet enrollment by the clinic, by site } \\
\text { Assess adaptation of training needed to improve InCharge Health implementation at } \\
\text { each site } \\
\text { - Engagement with the app: percentage, number, and representativeness of patients } \\
\text { who used InCharge Health during the study period (low, medium-low, medium, or } \\
\text { high use; in the entire practice) } \\
\text { - Proportion, number, and characteristics of patients who complete the study among } \\
\text { those who initiate the use of the app but then later discontinue at each site } \\
\text { - Percentage and characteristics of patients who reported satisfaction with the InCharge } \\
\text { Health app (MARS }{ }^{\mathrm{k}} \text { scale) } \\
\text { Clinic/provider assessment of perceptions of InCharge Health app for further scale- } \\
\text { up or sustainability-ease of use, preferred features, and so on }\end{array}$ & $\begin{array}{l}\text { - } \quad \text { App usage statistics } \\
\text { - } \quad \text { Patient surveys } \\
\text { - }\end{array}$ \\
\hline Maintenance/sustainability & $\begin{array}{l}\text { - Extent to which program leaders express a desire or intent to continue providing the } \\
\text { app with patients at the conclusion of the research } \\
\text { - Percentage of patients who continue to use the app beyond the study period and their } \\
\text { representativeness }\end{array}$ & $\begin{array}{l}\text { - Pharmacy claims data } \\
\text { (PDC for hydroxyurea } \\
\text { refills) } \\
\text { - App use statistics } \\
\text { - Clinic data collection } \\
\text { - } \quad \text { Qualitative interviews }\end{array}$ \\
\hline
\end{tabular}

${ }^{\mathrm{a}} \mathrm{PDC}$ : proportion of days covered.

${ }^{\mathrm{b}} \mathrm{ED}$ : emergency department.

${ }^{\mathrm{c}} \mathrm{MCV}$ : mean corpuscular volume.

${ }^{\mathrm{d}}$ ANC: absolute neutrophil count.

${ }^{\mathrm{e}} \mathrm{ARC}$ : absolute reticulocyte count.

${ }^{\mathrm{f}} \mathrm{HbF}$ : fetal hemoglobin.

${ }^{\mathrm{g}} \mathrm{Hb}$ : hemoglobin.

${ }^{\mathrm{h}} \mathrm{LDH}$ : lactate dehydrogenase.

${ }^{\mathrm{i}}$ ASCQ-Me: adult sickle cell quality of life measurement information system.

${ }^{j}$ PROMIS: Patient-Reported Outcomes Measurement Information System.

${ }^{\mathrm{k}}$ MARS: mobile app rating scale. 
Table 4. The reach, effectiveness, adoption, implementation, and maintenance evaluation measures of Hydroxyurea Toolbox implementation.

\begin{tabular}{|c|c|c|}
\hline Domains & Measures & Data sources \\
\hline Adoption—clinic & $\begin{array}{l}\text { - Proportion and representativeness of clinics that agree to } \\
\text { support the } H U^{\mathrm{a}} \text { Toolbox }\end{array}$ & $\begin{array}{l}\text { - Institutional data to describe clinics (eg, size, case } \\
\text { mix, years in service, regional sociodemographics } \\
\text { of } \mathrm{SCD}^{\mathrm{b}} \text { patients) } \\
\text { - } \quad \text { Clinic data collection form } \\
\text { - } \quad \text { Qualitative interviews }\end{array}$ \\
\hline Adoption-provider & $\begin{array}{l}\text { Characteristics of providers at each site (eg, specialty, } \\
\text { years in practice, sociodemographics, level of expertise) } \\
\text { Proportion and representativeness of eligible providers } \\
\text { approached in the study (numerator) among all providers } \\
\text { (denominator) } \\
\text { - Proportion and representativeness of enrolled providers in } \\
\text { the study (numerator) among all eligible providers (denom- } \\
\text { inator) at each site }\end{array}$ & $\begin{array}{ll}\text { - } & \text { Provider survey } \\
\text { - } & \text { Clinic data collection form }\end{array}$ \\
\hline Effectiveness & $\begin{array}{l}\text { - Number and proportion of providers demonstrating im- } \\
\text { proved knowledge and self-efficacy in hydroxyurea admin- } \\
\text { istration } \\
\text { - Percentage of patients who were prescribed hydroxyurea } \\
\text { per provider }\end{array}$ & $\begin{array}{ll}\text { - } & \text { Provider survey } \\
\text { - } & \text { Medical chart abstraction } \\
& \text { Qualitative interviews }\end{array}$ \\
\hline Implementation & $\begin{array}{l}\text { - Consistency with which sites are able to implement the } \\
\text { use of the Toolbox app as planned } \\
\text { Engagement with the app: Percentage, number, and repre- } \\
\text { sentativeness of providers that appropriately used } H U \\
\text { Toolbox app (low or high use; in the entire practice) } \\
\text { - Percentage of providers who reported satisfaction with } H U \\
\text { Toolbox app (MARS }{ }^{\mathrm{c}} \text { scale) } \\
\text { - Percentage of patients whose provider used the Toolbox } \\
\text { at each site } \\
\text { - App usage statistics }\end{array}$ & $\begin{array}{ll}\text { - } & \text { App usage statistics } \\
\text { - } & \text { Provider survey } \\
\text { - } & \text { Qualitative interviews }\end{array}$ \\
\hline Maintenance/sustainability & $\begin{array}{l}\text { Extent to which program leaders express a desire or intent } \\
\text { to offer or encourage the use of the Toolbox app by their } \\
\text { clinical providers at the conclusion of the research } \\
\text { Percentage of providers who continue to use the provider } \\
\text { app beyond the study period, and representativeness } \\
\text { - Percentage of providers who continue to prescribe hydrox- } \\
\text { yurea to their patients }\end{array}$ & $\begin{array}{ll}- & \text { App usage statistics } \\
\text { - } & \text { Clinic data collection form } \\
\text { - } & \text { Qualitative interviews }\end{array}$ \\
\hline
\end{tabular}

${ }^{\mathrm{a}} \mathrm{HU}$ : Hydroxyurea.

${ }^{\mathrm{b}}$ MARS: mobile app rating scale.

${ }^{\mathrm{b}} \mathrm{SCD}$ : sickle cell disease.

\section{Sample Size}

Sample sizes were calculated for the primary outcome, PDC, using simulations based on the linear mixed model in the analysis plan. First, we modeled the baseline values. Results from Candrilli et al [18] indicated a left-skewed distribution for adherence measured by medication possession ratio. We expect a similarly left-skewed distribution for PDC. The baseline PDC was therefore modeled as $\mathrm{PDC}=100 \times X$, where $X$ follows a beta distribution with parameters 1.0 and 0.6667 . This produced a left-skewed distribution with a mean of $60 \%$ (SD 30\%), closely paralleling a mean of 0.60 (SD 0.32) reported by Candrilli et al [18] for the medication possession ratio. We included site-to-site variation in baseline PDC by adding a site-specific random variate, drawn from a normal distribution with a mean of 0 (SD $0.2)$ to the 2 parameters. The resulting site-specific means are between $56 \%$ and $69 \%$, with a probability of .95 . Baseline values were modeled by drawing random samples from these beta distributions.

To model treatment response, including site-to-site variation in response, we added the expected response of $12 \%$ plus a site-specific random variable drawn from a normal distribution with a mean of 0 (SD 5.48) to each baseline value for PDC. Residual intrasubject variation at each time point (in the linear mixed model) was included by adding a separate random variable drawn from a normal distribution with a mean of 0 to each simulated PDC value. Assuming that approximately $25 \%$ of 24-week PDC values will be missing, each 24-week observation was randomly deleted with a probability of 25 .

The treatment effect is measured against noise, which includes residual intrasubject variation and site-to-site variation in treatment response. Therefore, power was investigated by specifying SDs for the 2 variance components, generating 
simulated data sets of 8 sites with 46 subjects recruited per site, and fitting the linear mixed model to each data set. Power was estimated as the percentage of simulated data sets producing a statistically significant increase in PDC among 1000 simulated data sets.

Baseline and posttreatment PDC are expected to be moderately to strongly correlated (ie, subjects with lower baseline PDC will tend to have lower posttreatment PDC than those with higher starting values). This expectation places limits on the variance components because the correlation varies inversely with the variance of the measurements. Variance components that result in a correlation of 0.50 also result in approximately $90 \%$ power to detect a treatment effect under the conditions specified in the simulations. A correlation of 0.50 is well below expectations, indicating that the study will have considerable power to detect the posited treatment effect under the specified conditions.

Patients who initiate hydroxyurea on the same day of enrollment will not contribute to the primary aim but will be analyzed as a separate subset of participants for the secondary outcomes only, as no baseline PDC will be able to be calculated for them. The total number of physicians and advanced practitioners in all participating sites is approximately 100 . All of them will be approached, and the total number of those who agree to participate will be computed.

\section{Methods of Analysis}

\section{Aim 1: Improve Patient Adherence to Hydroxyurea}

Changes in PDC in response to treatment will be evaluated using a linear mixed model. Predictors will include a random effect for the study site, a fixed binary indicator for treatment, the interaction of the site with treatment, and a random effect for the subject nested within the site. The interaction is included to test for differences in PDC changes among sites. The random subject effect is included to account for the correlation induced by repeated observations of the same subjects. If the interaction is not statistically significant, then it will be dropped from the model, and inferences about treatment response will be based on the main effect of treatment. If the treatment does indicate site-to-site variation in change in PDC, then pairwise comparisons between changes at the sites will be made using the Tukey honestly significant difference to control the type I error rate.

\section{Aim 1a: To Assess Patient Engagement and Behaviors Related to the Use of InCharge Health}

Counts and scores of the measures in Textboxes 1 and 2 will be graphed with box plots by month. Using the box plots from the last month, patients will be classified into 4 levels of app usability: low ( $<25 \%$ of the daily app usage), medium-low (25\%-49\% of the daily app usage), medium-high (50\%-74\% of the daily app usage) or high (75\%-100\% of the daily app usage) by initially using quartiles of the implementation measures, then examining the box plots of the measures and adjusting as needed to create 4 clinically meaningful groupings of app users. App uptake will be computed at the end of the study at each site.

\section{Aim 1b: To Examine the Improvement in Clinical and Patient Outcomes Related to the Use of InCharge Health}

The linear mixed model will also be employed to evaluate changes in laboratory biomarkers of hydroxyurea effect, quality of life, health literacy, self-efficacy, and satisfaction with the app (as listed in Textboxes 1 and 2) between baseline and 24 weeks. The models will include the treatment indicator and site as usual, a 4-level categorical predictor of use of the app (low, medium-low, medium-high, and high) and the interaction of app use with the treatment. A statistically significant interaction will be interpreted to mean that changes in an outcome in response to the treatment varied with use of the app. The Tukey HSD test will then be employed to identify the pairwise differences that contributed to the significant effect. If no variation with use of the app is found, then the interaction will be dropped from the model as described earlier. The models for laboratory biomarkers will also include time since starting hydroxyurea and sickle cell genotype as covariates. Models, including site-level characteristics of urban versus rural and academic versus community will also be created to determine if heterogeneity in the site characteristics impacts intervention efficacy. For dichotomous outcomes, such as PDC $\geq 80 \%$ versus $<80 \%$ and hospitalization and emergency room visits during the study, generalized linear mixed models (GLMM) will be employed with a logit link to relate the outcome to the predictors [65]. The GLMM models will follow the same format as the linear mixed model above with fixed effects for intervention/app use and random effects for sites and subjects within sites.

\section{Aim 2: Improve Provider Hydroxyurea Prescribing Behaviors}

Given the limited number of providers expected to enroll in the study, many of the analyses are simplified and do not account for the across the site and across time complexities of the study design. As such, the results should be considered exploratory. Using baseline data, providers will be classified into 4 categories, according to the level of comfort and expertise in caring for patients with SCD (Multimedia Appendix 2). We will attempt to evaluate the implementation and effectiveness outcomes stratified by this provider categorization to better understand how expertise impacts the implementation and effectiveness of the HU Toolbox app.

\section{Aim 2a: To Examine Clinic Characteristics and Provider Engagement and Behaviors Related to the Use of the HU Toolbox}

Uptake of the HU Toolbox by providers after 9 months will be assessed using the implementation measures identified in Table 4 (under implementation). Box plots for each measure for all participants will be combined and stratified by expertise level. One-way analysis of variance or Kruskal-Wallis tests will examine differences in the uptake of the $H U$ Toolbox across expertise levels (Figure 5). If the null hypothesis is rejected, Dunn's test will be employed for multiple comparisons. If an experience level has fewer than 5 providers, it will be combined with the closest lower experience level. The results of these analyses will be used to identify clinically meaningful low and high toolbox app uptake groups for Aim $2 \mathrm{~b}$. 
Figure 5. Study group comparisons according to each aim. The introduction and investigation of each intervention is performed sequentially. A total of 4 possible intervention combinations will be evaluated and compared: provider and patient use the intervention (patient and provider blue boxes), neither provider nor patient uses the intervention (patient and provider blue boxes), provider uses the intervention, but the patient does not (provider: blue box and patient: red box), and the patient uses the intervention, but the provider does not (provider red box and patient blue box). HU Toolbox: Hydroxyurea Toolbox; SCD: sickle cell disease.

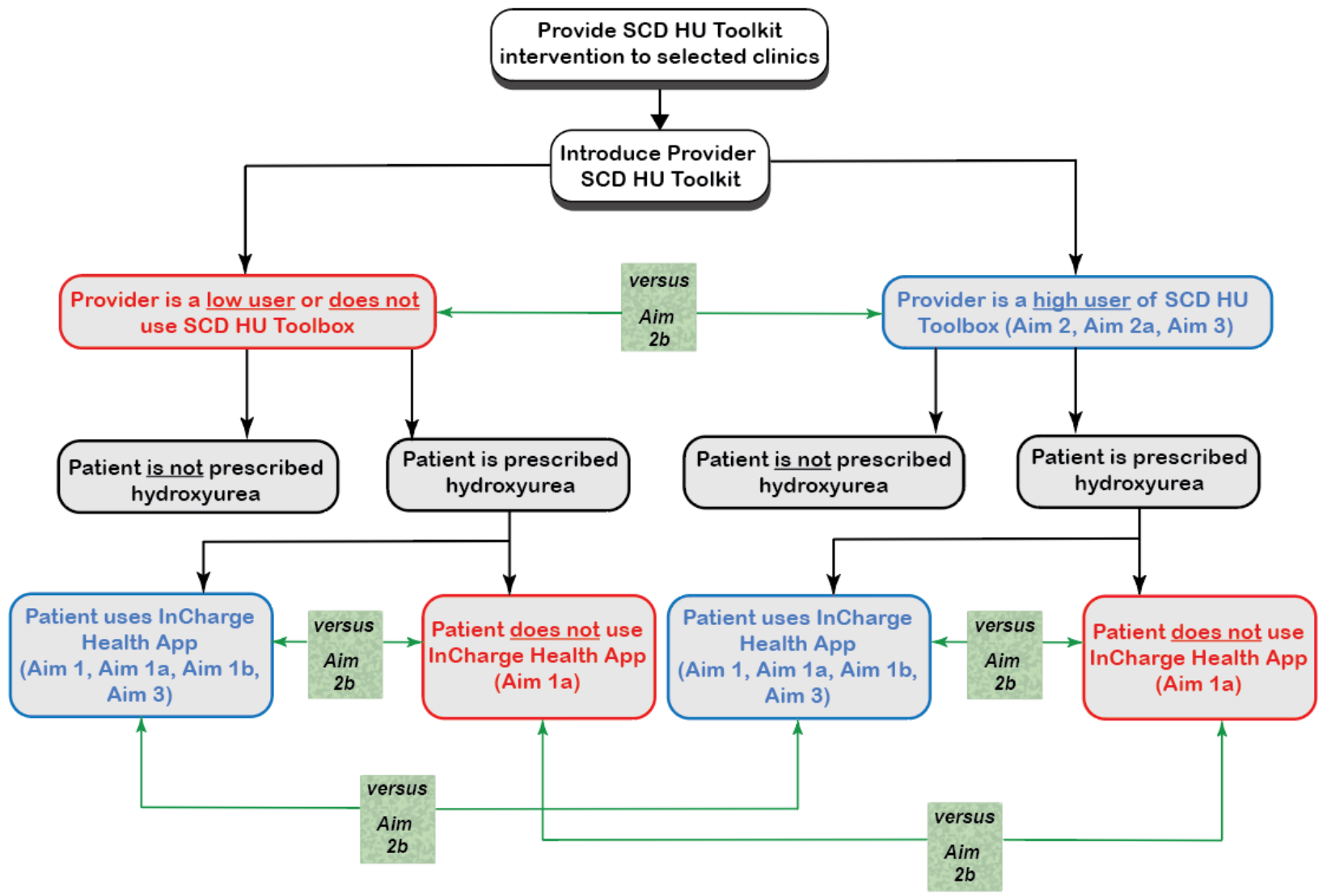

\section{Aim 2b: To Assess the Combined Effects of the Patient and Provider Mobile Health Interventions on Hydroxyurea Adherence and Health Care Utilization}

Figure 5 shows the sequential introduction and investigation of each intervention. A total of 4 possible intervention combinations will be evaluated and compared: provider and patient use the intervention, neither provider nor patient uses the intervention, the provider uses the intervention, but the patient does not, and the patient uses the intervention, but the provider does not. Comparisons within and across groups will be conducted. This analysis seeks to identify the impact of both the patient and provider interventions on hydroxyurea adherence and acute health care utilization (count of emergency department visits and hospitalizations per patient) at baseline and at 6 months. These outcomes will be treated as Poisson variables in GLMMs with $\log$ link functions. Predictors will include an indicator for time (baseline vs 6 months), a categorical predictor for the 4 levels of InCharge Health app uptake defined in Aim 1a, an indicator for low (less than one day per month use of the app in a 6-month period) versus high provider (one or more days per month use of the app in a 6-month period) toolkit app uptake, the interaction between patient and provider uptake, and a random effect to account for clustering of baseline and 9-month measures within providers. The Tukey HSD test will be employed for pairwise comparisons among predictor categories if statistically significant effects of patient characteristics, provider characteristics, or interactions are found. App uptake will be computed at the end of the study at each site.

\section{Aim 3: Qualitatively Evaluate the Barriers and Facilitators of the Implementation of Mobile Health Interventions}

Sufficient understanding of the contextual factors in the implementation of mHealth interventions is critical to ensuring future scale-up and translation of study findings [66]. As such, for Aim 3, we will build on the RE-AIM quantitative findings by using qualitative inquiry to identify common barriers and facilitators across the sites and to support the development of implementation strategies for use in future studies. Data will be collected and analyzed concurrently using a mixed methods approach, where qualitative data will be secondary to the quantitative assessment [67].

\section{Results}

The study is currently enrolling participants (NCT 04080167). Recruitment is anticipated to be completed by mid-2021. The results are expected to be submitted for publication toward the end of the project in early 2022. 


\section{Discussion}

Hydroxyurea has proven its efficacy in treating patients with SCD, but its utilization in real-world settings is suboptimal. mHealth interventions have increasingly been used to foster greater adherence to medication and to facilitate the use of therapies by prescribers. In this study, we propose to overcome the barriers to hydroxyurea utilization by using a 2-level mHealth intervention: the InCharge Health app for patients and the HU Toolbox app for providers. We will examine the uptake of these 2 interventions using implementation science strategies. Although acknowledging the multilevel barriers to hydroxyurea utilization, our approach will address the main barriers affecting hydroxyurea adoption and use among patients with SCD and focus on improving prescribing practices among providers. This 2-level approach will allow us to demonstrate the clinical effect of mHealth interventions to improve adherence among patients (the main outcome of the study) and, at the same time, address and evaluate other barriers to optimal care among providers. Our findings will enhance the subsequent implementation of mHealth in diverse settings and populations, as the participating sites are substantially different in geographical settings (eg, urban, suburban, and rural) and population characteristics. The study will provide preliminary data on the integration of mHealth into clinical care, its clinical influence, and evaluate how well this strategy is accepted, adopted, and sustained in diverse clinical settings.

The Integration of mHealth into SCD Care to Increase Hydroxyurea Utilization study will be the first large-scale prospective trial to investigate mHealth interventions for SCD using an implementation science framework to improve hydroxyurea effectiveness and adaptation while incorporating implementation strategies to maximize the integration of the apps into clinical practice. If successful, this model may create a new paradigm in which mHealth interventions can be integrated into routine clinical practice in real-world settings. This approach focuses on the complexity of therapies for chronic diseases in which the lack of widespread adaptation is multifactorial and should account for multiple stakeholders.

This study has some limitations. PDC is one of the multiple measures of medication adherence; however, it allows us to pragmatically estimate adherence as it approximates optimal adherence when PDC is $\geq 80 \%$. PDC is an accepted quality measure of adherence and the metric used by the Centers for Medicare and Medicaid Services as the process measure of adherence [68]. PDC best reflects the real-world setting as opposed to the use of electronic bottles or video-recorded daily dose ingestion (ie, directly observed adherence measure). The Integration of mHealth into SCD Care to Increase Hydroxyurea Utilization study does not include randomization of mHealth interventions, and this approach may be considered as the next step in our research.

Few prospective intervention studies to improve hydroxyurea adherence in SCD using mHealth have been undertaken [42]. In general, they have shown positive results in improving daily hydroxyurea utilization and other outcomes, such as health-related quality of life $[69,70]$. The Integration of mHealth into SCD Care to Increase Hydroxyurea Utilization study expands the existing studies because it (1) addresses all the important behavior determinants of suboptimal hydroxyurea utilization at both the patient and provider levels, (2) incorporates them into mHealth apps for both patients and providers, and (3) studies a large population of patients with SCD and their providers in different geographic and clinical settings. Finally, engagement with mHealth interventions will be of particular importance during the study, as sustained use of mHealth intervention may decrease over time. Our study plans to evaluate engagement with mHealth interventions by monitoring app usability (frequency of use and specific features used) in addition to performing qualitative analysis to better ascertain factors influencing engagement with mHealth.

In summary, the Integration of mHealth into SCD Care to Increase Hydroxyurea Utilization study is the first study investigating the efficacy and implementation of mHealth interventions on 2 levels to improve hydroxyurea utilization, namely the patient and the provider, in a large multicenter prospective study. Importantly, the development of both mHealth interventions was informed by the stakeholders involved (patients with SCD and their providers). If successful, this study will help define the role of mHealth in increasing hydroxyurea utilization at multiple levels and will allow for a large-scale implementation trial that will rigorously test which strategies are most effective in disseminating mHealth to more patients with SCD and their providers.

\section{Acknowledgments}

At the time of submission, this study was approved by the Institutional Review Board of the St. Jude's Children's Research Hospital (19-0159). The full protocol and study manual of procedures are available from the corresponding author upon request. The SCD Implementation Consortium has been supported by the US Federal Government cooperative agreements HL133948, HL133964, HL133990, HL133996, HL133994, HL133997, HL134004, HL134007, and HL134042 from the NHLBI and the National Institute on Minority Health and Health Disparities (Bethesda, Maryland).

\section{Authors' Contributions}

JH, NS, LD, DB, MF, RG, VG, RL, AK, CM, JS, TW, MT, CC, AB, MP, LK, and HB conceived the study. All authors contributed to refining the study design and finalizing the protocol. $\mathrm{JH}$ drafted the initial and final versions of the manuscript. All authors have read and approved the final manuscript. 


\section{Conflicts of Interest}

JH receives research funds from Global Blood Therapeutics and Novartis, and consultant fees from MJH Life Sciences. NS receives research funding from Global Blood Therapeutics, Imara and Novartis, is a paid speaker for Novartis, Global Blood Therapeutics, Alexion, and is a consultant for Novartis and Commonwealth Serum Laboratories Behring. HB receives research funding from Sanofi, Otsuka, Improved Patient Outcomes, Novo Nordisk, and is a consultant for Novartis, Sanofi, and Abbott.

\section{Multimedia Appendix 1}

SPIRIT checklist.

[DOC File, 123 KB-Multimedia Appendix 1]

\section{Multimedia Appendix 2}

Categorization of providers according to expertise level (classification developed by Dr Wally R Smith and Dr Richard Lottenberg). [PNG File, 44 KB-Multimedia Appendix 2]

\section{Multimedia Appendix 3}

List of sickle cell disease implementation consortium investigators.

[DOCX File, 26 KB-Multimedia Appendix 3]

\section{References}

1. Hassell K. Population estimates of sickle cell disease in the US. Am J Prev Med 2010 Apr;38(4 Suppl):S512-S521. [doi: 10.1016/j.amepre.2009.12.022] [Medline: 20331952]

2. Charache S, Terrin ML, Moore RD, Dover GJ, Barton FB, Eckert SV, et al. Effect of hydroxyurea on the frequency of painful crises in sickle cell anemia. Investigators of the multicenter study of hydroxyurea in sickle cell anemia. $\mathrm{N}$ Engl J Med 1995 May 18;332(20):1317-1322. [doi: 10.1056/NEJM199505183322001] [Medline: 7715639]

3. Wang WC, Oyeku SO, Luo Z, Boulet SL, Miller ST, Casella JF, BABY HUG Investigators. Hydroxyurea is associated with lower costs of care of young children with sickle cell anemia. Pediatrics 2013 Oct;132(4):677-683 [FREE Full text] [doi: 10.1542/peds.2013-0333] [Medline: 23999955]

4. Wang W, Ware R, Miller S, Iyer R, Casella J, Minniti C, BABY HUG Investigators. Hydroxycarbamide in very young children with sickle-cell anaemia: a multicentre, randomised, controlled trial (BABY HUG). Lancet 2011 May 14;377(9778):1663-1672 [FREE Full text] [doi: 10.1016/S0140-6736(11)60355-3] [Medline: 21571150]

5. Thornburg CD, Files BA, Luo Z, Miller ST, Kalpatthi R, Iyer R, BABY HUG Investigators. Impact of hydroxyurea on clinical events in the BABY HUG trial. Blood 2012 Nov 22;120(22):4304-10; quiz 4448 [FREE Full text] [doi: 10.1182/blood-2012-03-419879] [Medline: 22915643]

6. Nottage KA, Hankins JS, Smeltzer M, Mzayek F, Wang WC, Aygun B, et al. Hydroxyurea use and hospitalization trends in a comprehensive pediatric sickle cell program. PLoS One 2013;8(8):e72077 [FREE Full text] [doi:

10.1371/journal.pone.0072077] [Medline: 23967276]

7. Stallworth JR, Jerrell JM, Tripathi A. Cost-effectiveness of hydroxyurea in reducing the frequency of pain episodes and hospitalization in pediatric sickle cell disease. Am J Hematol 2010 Oct;85(10):795-797 [FREE Full text] [doi: 10.1002/ajh.21772] [Medline: 20645429]

8. Steinberg MH, Barton F, Castro O, Pegelow CH, Ballas SK, Kutlar A, et al. Effect of hydroxyurea on mortality and morbidity in adult sickle cell anemia: risks and benefits up to 9 years of treatment. J Am Med Assoc 2003 Apr 2;289(13):1645-1651. [doi: 10.1001/jama.289.13.1645] [Medline: 12672732]

9. Voskaridou E, Christoulas D, Bilalis A, Plata E, Varvagiannis K, Stamatopoulos G, et al. The effect of prolonged administration of hydroxyurea on morbidity and mortality in adult patients with sickle cell syndromes: results of a 17-year, single-center trial (LaSHS). Blood 2010 Mar 25;115(12):2354-2363. [doi: 10.1182/blood-2009-05-221333] [Medline: 19903897]

10. Lobo CL, Pinto JF, Nascimento EM, Moura PG, Cardoso GP, Hankins JS. The effect of hydroxcarbamide therapy on survival of children with sickle cell disease. Br J Haematol 2013 Jun;161(6):852-860. [doi: 10.1111/bjh.12323] [Medline: 23590693]

11. Lê PQ, Gulbis B, Dedeken L, Dupont S, Vanderfaeillie A, Heijmans C, et al. Survival among children and adults with sickle cell disease in Belgium: benefit from hydroxyurea treatment. Pediatr Blood Cancer 2015 Nov;62(11):1956-1961. [doi: 10.1002/pbc.25608] [Medline: 26173735]

12. Ware R. How I use hydroxyurea to treat young patients with sickle cell anemia. Blood 2010 Jul 1;115(26):5300-5311 [FREE Full text] [doi: 10.1182/blood-2009-04-146852] [Medline: 20223921] 
13. Yawn BP, Buchanan GR, Afenyi-Annan AN, Ballas SK, Hassell KL, James AH, et al. Management of sickle cell disease: summary of the 2014 evidence-based report by expert panel members. J Am Med Assoc 2014 Sep 10;312(10):1033-1048. [doi: 10.1001/jama.2014.10517] [Medline: 25203083]

14. Brawley OW, Cornelius LJ, Edwards LR, Gamble VN, Green BL, Inturrisi C, et al. National institutes of health consensus development conference statement: hydroxyurea treatment for sickle cell disease. Ann Intern Med 2008 Jun 17;148(12):932-938. [doi: 10.7326/0003-4819-148-12-200806170-00220] [Medline: 18458271]

15. Lanzkron S, Strouse JJ, Wilson R, Beach MC, Haywood C, Park H, et al. Systematic review: hydroxyurea for the treatment of adults with sickle cell disease. Ann Intern Med 2008 Jun 17;148(12):939-955 [FREE Full text] [doi: 10.7326/0003-4819-148-12-200806170-00221] [Medline: 18458272]

16. Ritho J, Liu H, Hartzema AG, Lottenberg R. Hydroxyurea use in patients with sickle cell disease in a medicaid population. Am J Hematol 2011 Oct;86(10):888-890 [FREE Full text] [doi: 10.1002/ajh.22134] [Medline: 21922530]

17. Lanzkron S, Haywood C, Fagan PJ, Rand CS. Examining the effectiveness of hydroxyurea in people with sickle cell disease. J Health Care Poor Underserved 2010 Feb;21(1):277-286. [doi: 10.1353/hpu.0.0272] [Medline: 20173269]

18. Candrilli SD, O'Brien SH, Ware RE, Nahata MC, Seiber EE, Balkrishnan R. Hydroxyurea adherence and associated outcomes among medicaid enrollees with sickle cell disease. Am J Hematol 2011 Mar;86(3):273-277 [FREE Full text] [doi: 10.1002/ajh.21968] [Medline: 21328441]

19. Lanzkron S, Haywood C, Hassell KL, Rand C. Provider barriers to hydroxyurea use in adults with sickle cell disease: a survey of the sickle cell disease adult provider network. J Natl Med Assoc 2008 Aug;100(8):968-973. [Medline: 18717150]

20. Lebensburger JD, Sidonio RF, Debaun MR, Safford MM, Howard TH, Scarinci IC. Exploring barriers and facilitators to clinical trial enrollment in the context of sickle cell anemia and hydroxyurea. Pediatr Blood Cancer 2013 Aug;60(8):1333-1337 [FREE Full text] [doi: 10.1002/pbc.24486] [Medline: 23418000]

21. Patel NG, Lindsey T, Strunk RC, DeBaun MR. Prevalence of daily medication adherence among children with sickle cell disease: a 1-year retrospective cohort analysis. Pediatr Blood Cancer 2010 Sep;55(3):554-556 [FREE Full text] [doi: 10.1002/pbc.22605] [Medline: 20658630]

22. Reeves SL, Jary HK, Gondhi JP, Raphael JL, Lisabeth LD, Dombkowski KJ. Hydroxyurea use among children with sickle cell anemia. Pediatr Blood Cancer 2019 Jun;66(6):e27721. [doi: 10.1002/pbc. 27721] [Medline: $\underline{30900800]}$

23. Haywood C, Beach MC, Bediako S, Carroll CP, Lattimer L, Jarrett D, et al. Examining the characteristics and beliefs of hydroxyurea users and nonusers among adults with sickle cell disease. Am J Hematol 2011 Jan;86(1):85-87 [FREE Full text] [doi: 10.1002/ajh.21883] [Medline: 21117058]

24. Crosby LE, Barach I, McGrady ME, Kalinyak KA, Eastin AR, Mitchell MJ. Integrating interactive web-based technology to assess adherence and clinical outcomes in pediatric sickle cell disease. Anemia 2012;2012:492428 [FREE Full text] [doi: 10.1155/2012/492428] [Medline: 22701785]

25. Thornburg CD, Calatroni A, Telen M, Kemper AR. Adherence to hydroxyurea therapy in children with sickle cell anemia. J Pediatr 2010 Mar;156(3):415-419 [FREE Full text] [doi: 10.1016/j.jpeds.2009.09.044] [Medline: 19880135]

26. Walsh KE, Cutrona SL, Kavanagh PL, Crosby LE, Malone C, Lobner K, et al. Medication adherence among pediatric patients with sickle cell disease: a systematic review. Pediatrics 2014 Dec;134(6):1175-1183 [FREE Full text] [doi: 10.1542/peds.2014-0177] [Medline: 25404717]

27. Strouse JJ, Heeney MM. Hydroxyurea for the treatment of sickle cell disease: efficacy, barriers, toxicity, and management in children. Pediatr Blood Cancer 2012 Aug;59(2):365-371 [FREE Full text] [doi: 10.1002/pbc.24178] [Medline: 22517797]

28. Oyeku SO, Driscoll MC, Cohen HW, Trachtman R, Pashankar F, Mullen C, et al. Parental and other factors associated with hydroxyurea use for pediatric sickle cell disease. Pediatr Blood Cancer 2013 Apr;60(4):653-658 [FREE Full text] [doi: 10.1002/pbc.24381] [Medline: 23129068]

29. Badawy SM, Thompson AA, Liem RI. Technology access and smartphone app preferences for medication adherence in adolescents and young adults with sickle cell disease. Pediatr Blood Cancer 2016 May;63(5):848-852. [doi: 10.1002/pbc.25905] [Medline: 26844685]

30. Smith KE, Schatz J. Working memory in children with neurocognitive effects from sickle cell disease: contributions of the central executive and processing speed. Dev Neuropsychol 2016;41(4):231-244 [FREE Full text] [doi: 10.1080/87565641.2016.1238474] [Medline: 27759435]

31. Vichinsky EP, Neumayr LD, Gold JI, Weiner MW, Rule RR, Truran D, Neuropsychological Dysfunction and Neuroimaging Adult Sickle Cell Anemia Study Group. Neuropsychological dysfunction and neuroimaging abnormalities in neurologically intact adults with sickle cell anemia. J Am Med Assoc 2010 May 12;303(18):1823-1831 [FREE Full text] [doi: 10.1001/jama.2010.562] [Medline: 20460621]

32. Jorgensen D, Metti A, Butters M, Mettenburg J, Rosano C, Novelli E. Disease severity and slower psychomotor speed in adults with sickle cell disease. Blood Adv 2017 Sep 26;1(21):1790-1795 [FREE Full text] [doi: 10.1182/bloodadvances.2017008219] [Medline: 29296825]

33. Badawy SM, Thompson AA, Lai J, Penedo FJ, Rychlik K, Liem RI. Adherence to hydroxyurea, health-related quality of life domains, and patients' perceptions of sickle cell disease and hydroxyurea: a cross-sectional study in adolescents and young adults. Health Qual Life Outcomes 2017 Jul 5;15(1):136 [FREE Full text] [doi: 10.1186/s12955-017-0713-x] [Medline: 28679417] 
34. Brandow AM, Jirovec DL, Panepinto JA. Hydroxyurea in children with sickle cell disease: practice patterns and barriers to utilization. Am J Hematol 2010 Aug;85(8):611-613 [FREE Full text] [doi: 10.1002/ajh.21749] [Medline: 20658592]

35. Zhou J, Han J, Nutescu EA, Gordeuk VR, Saraf SL, Calip GS. Hydroxycarbamide adherence and cumulative dose associated with hospital readmission in sickle cell disease: a 6-year population-based cohort study. Br J Haematol 2018 Jul;182(2):259-270 [FREE Full text] [doi: 10.1111/bjh.15396] [Medline: 29767446]

36. Badawy SM, Thompson AA, Holl JL, Penedo FJ, Liem RI. Healthcare utilization and hydroxyurea adherence in youth with sickle cell disease. Pediatr Hematol Oncol 2018;35(5-6):297-308. [doi: 10.1080/08880018.2018.1505988] [Medline: 30636474]

37. Mensah GA, Engelgau M, Stoney C, Mishoe H, Kaufmann P, Freemer M, Trans-NHLBI T4 Translation Research Work Groups. News from NIH: a center for translation research and implementation science. Transl Behav Med 2015 Jun;5(2):127-130 [FREE Full text] [doi: 10.1007/s13142-015-0310-7] [Medline: 26029274]

38. DiMartino LD, Baumann AA, Hsu LL, Kanter J, Gordeuk VR, Glassberg J, Sickle Cell Disease Implementation Consortium. The sickle cell disease implementation consortium: translating evidence-based guidelines into practice for sickle cell disease. Am J Hematol 2018 Dec;93(12):E391-E395 [FREE Full text] [doi: 10.1002/ajh.25282] [Medline: 30203558]

39. Palmer M, Barnard S, Perel P, Free C. Mobile phone-based interventions for improving adherence to medication prescribed for the primary prevention of cardiovascular disease in adults. Cochrane Database Syst Rev 2018 Jun 22;6:CD012675 [FREE Full text] [doi: 10.1002/14651858.CD012675.pub2] [Medline: 29932455]

40. Farzandipour M, Nabovati E, Sharif R, Arani M, Anvari S. Patient self-management of asthma using mobile health applications: a systematic review of the functionalities and effects. Appl Clin Inform 2017 Oct;8(4):1068-1081 [FREE Full text] [doi: 10.4338/ACI-2017-07-R-0116] [Medline: 29241254]

41. Mohammadi R, Tafti MA, Hoveidamanesh S, Ghanavati R, Pournik O. Reflection on mobile applications for blood pressure management: a systematic review on potential effects and initiatives. Stud Health Technol Inform 2018;247:306-310. [Medline: 29677972]

42. Badawy SM, Cronin RM, Hankins J, Crosby L, DeBaun M, Thompson AA, et al. Patient-centered ehealth interventions for children, adolescents, and adults with sickle cell disease: systematic review. J Med Internet Res 2018 Jul 19;20(7):e10940 [FREE Full text] [doi: $\underline{10.2196 / 10940]}$ [Medline: $\underline{\text { 30026178] }}$

43. Estepp JH, Winter B, Johnson M, Smeltzer MP, Howard SC, Hankins JS. Improved hydroxyurea effect with the use of text messaging in children with sickle cell anemia. Pediatr Blood Cancer 2014 Nov;61(11):2031-2036. [doi: 10.1002/pbc.25177] [Medline: 25132074]

44. Schatz J, Schlenz AM, McClellan CB, Puffer ES, Hardy S, Pfeiffer M, et al. Changes in coping, pain, and activity after cognitive-behavioral training: a randomized clinical trial for pediatric sickle cell disease using smartphones. Clin J Pain 2015 Jun;31(6):536-547 [FREE Full text] [doi: 10.1097/AJP.0000000000000183] [Medline: 25503599]

45. Shah N, Jonassaint J, de Castro L. Patients welcome the sickle cell disease mobile application to record symptoms via technology (SMART). Hemoglobin 2014;38(2):99-103. [doi: 10.3109/03630269.2014.880716] [Medline: 24512633]

46. Creary SE, Gladwin MT, Byrne M, Hildesheim M, Krishnamurti L. A pilot study of electronic directly observed therapy to improve hydroxyurea adherence in pediatric patients with sickle-cell disease. Pediatr Blood Cancer 2014 Jun;61(6):1068-1073. [doi: 10.1002/pbc.24931] [Medline: 24436121]

47. Creary S, Chisolm D, Stanek J, Hankins J, O'Brien SH. A multidimensional electronic hydroxyurea adherence intervention for children with sickle cell disease: single-arm before-after study. JMIR Mhealth Uhealth 2019 Aug 8;7(8):e13452 [FREE Full text] [doi: 10.2196/13452] [Medline: 31397291]

48. Silveira DV, Marcolino MS, Machado EL, Ferreira CG, Alkmim MB, Resende ES, et al. Development and evaluation of a mobile decision support system for hypertension management in the primary care setting in Brazil: mixed-methods field study on usability, feasibility, and utility. JMIR Mhealth Uhealth 2019 Mar 25;7(3):e9869 [FREE Full text] [doi: 10.2196/mhealth.9869] [Medline: 30907740]

49. Klingberg A, Wallis LA, Hasselberg M, Yen P, Fritzell SC. Teleconsultation using mobile phones for diagnosis and acute care of burn injuries among emergency physicians: mixed-methods study. JMIR Mhealth Uhealth 2018 Oct 19;6(10):e11076 [FREE Full text] [doi: 10.2196/11076] [Medline: 30341047]

50. Lim J, Cloete G, Dunsmuir DT, Payne BA, Scheffer C, von Dadelszen P, et al. Usability and feasibility of PIERS on the move: an mhealth app for pre-eclampsia triage. JMIR Mhealth Uhealth 2015 Apr 17;3(2):e37 [FREE Full text] [doi: 10.2196/mhealth.3942] [Medline: 25887292]

51. Moore S, Jayewardene D. The use of smartphones in clinical practice. Nurs Manag (Harrow) 2014 Jul;21(4):18-22. [doi: 10.7748/nm.21.4.18.e1225] [Medline: 24967805]

52. Fernandez ME, Ruiter RA, Markham CM, Kok G. Intervention mapping: theory- and evidence-based health promotion program planning: perspective and examples. Front Public Health 2019;7:209 [FREE Full text] [doi: 10.3389/fpubh.2019.00209] [Medline: 31475126]

53. Stretcher V, Rosenstock I. The health belief model. In: Glanz K, Rimer BK, Viswanath K, editors. Health Behavior and Health Education: Theory, Research, and Practice. San Francisco, CA: Jossey-Bass; 1997.

54. Davis FD. Perceived usefulness, perceived ease of use, and user acceptance of information technology. MIS Q 1989 Sep;13(3):319. [doi: 10.2307/249008] 
55. Venkatesh V, Davis FD. A model of the antecedents of perceived ease of use: development and test. Decis Sci 1996 Sep;27(3):451-481. [doi: 10.1111/j.1540-5915.1996.tb01822.x]

56. Wu J, Wang S, Lin L. Mobile computing acceptance factors in the healthcare industry: a structural equation model. Int J Med Inform 2007 Jan;76(1):66-77. [doi: 10.1016/j.ijmedinf.2006.06.006] [Medline: 16901749]

57. Alberts NM, Badawy SM, Hodges J, Estepp JH, Nwosu C, Khan H, et al. Development of the InCharge Health Mobile App to Improve Adherence to Hydroxyurea in Patients With Sickle Cell Disease: User-Centered Design Approach. JMIR Mhealth Uhealth 2020 May 08;8(5):e14884-e14821 [FREE Full text] [doi: 10.2196/14884] [Medline: 32383683]

58. Bijlsma MJ, Janssen F, Hak E. Estimating time-varying drug adherence using electronic records: extending the proportion of days covered (PDC) method. Pharmacoepidemiol Drug Saf 2016 Mar;25(3):325-332. [doi: 10.1002/pds.3935] [Medline: 26687394]

59. Pernell B, DeBaun M, Becker K, Rodeghier M, Bryant V, Cronin R. Improving medication adherence with two-way short message service reminders in sickle cell disease and asthma. A feasibility randomized controlled trial. Appl Clin Inform 2017 May 24;8(2):541-559 [FREE Full text] [doi: 10.4338/ACI-2016-12-RA-0203] [Medline: 28536723]

60. Chan A, Tetzlaff J, Altman D, Laupacis A, Gøtzsche PC, Krleža-Jerić K, et al. SPIRIT 2013 statement: defining standard protocol items for clinical trials. Ann Intern Med 2013 Feb 5;158(3):200-207 [FREE Full text] [doi: 10.7326/0003-4819-158-3-201302050-00583] [Medline: 23295957]

61. Shoup JA, Gaglio B, Varda D, Glasgow RE. Network analysis of RE-AIM framework: chronology of the field and the connectivity of its contributors. Transl Behav Med 2015 Jun;5(2):216-232 [FREE Full text] [doi: 10.1007/s13142-014-0300-1] [Medline: 26029284]

62. Quanbeck A, Gustafson DH, Marsch LA, Chih MY, Kornfield R, McTavish F, et al. Implementing a mobile health system to integrate the treatment of addiction into primary care: a hybrid implementation-effectiveness study. J Med Internet Res 2018 Jan 30;20(1):e37 [FREE Full text] [doi: 10.2196/jmir.8928] [Medline: 29382624]

63. Glasgow RE, Harden SM, Gaglio B, Rabin B, Smith ML, Porter GC, et al. RE-AIM planning and evaluation framework: adapting to new science and practice with a 20-year review. Front Public Health 2019;7:64 [FREE Full text] [doi: 10.3389/fpubh.2019.00064] [Medline: 30984733]

64. Stoyanov SR, Hides L, Kavanagh DJ, Zelenko O, Tjondronegoro D, Mani M. Mobile app rating scale: a new tool for assessing the quality of health mobile apps. JMIR Mhealth Uhealth 2015 Mar 11;3(1):e27 [FREE Full text] [doi: 10.2196/mhealth.3422] [Medline: 25760773]

65. Baio G, Copas A, Ambler G, Hargreaves J, Beard E, Omar RZ. Sample size calculation for a stepped wedge trial. Trials 2015 Aug 17;16(1):354 [FREE Full text] [doi: 10.1186/s13063-015-0840-9] [Medline: 26282553]

66. Bakken S, Ruland CM. Translating clinical informatics interventions into routine clinical care: how can the RE-AIM framework help? J Am Med Inform Assoc 2009;16(6):889-897 [FREE Full text] [doi: 10.1197/jamia.M3085] [Medline: 19717799]

67. Palinkas LA, Aarons GA, Horwitz S, Chamberlain P, Hurlburt M, Landsverk J. Mixed method designs in implementation research. Adm Policy Ment Health 2011 Jan;38(1):44-53 [FREE Full text] [doi: 10.1007/s10488-010-0314-z] [Medline: 20967495]

68. Bosworth HB. Enhancing Medication Adherence: The Public Health Dilemma. New York, USA: Springer Healthcare; 2012.

69. Green NS, Manwani D, Matos S, Hicks A, Soto L, Castillo Y, et al. Randomized feasibility trial to improve hydroxyurea adherence in youth ages 10-18 years through community health workers: the HABIT study. Pediatr Blood Cancer 2017 Dec;64(12):e26689 [FREE Full text] [doi: 10.1002/pbc.26689] [Medline: 28643377]

70. Smaldone A, Findley S, Manwani D, Jia H, Green NS. HABIT, a randomized feasibility trial to increase hydroxyurea adherence, suggests improved health-related quality of life in youths with sickle cell disease. J Pediatr 2018 Jun;197:177-85.e2 [FREE Full text] [doi: 10.1016/j.jpeds.2018.01.054] [Medline: 29571930]

\author{
Abbreviations \\ ANOVA: analysis of variance \\ ED: emergency department \\ GLMM: generalized linear mixed models \\ HbF: fetal hemoglobin \\ HBM: health belief model \\ HU Toolbox: Hydroxyurea Toolbox \\ LDH: lactate dehydrogenase \\ LMM: linear mixed model \\ MARS: mobile app rating scale \\ MCV: mean corpuscular volume \\ mHealth: mobile health \\ MTD: maximum tolerated dose
}


NHLBI: National Heart, Lung, and Blood Institute

NIH: National Institutes of Health

PDC: proportion of daily coverage

PROMIS: Patient-Reported Outcomes Measurement Information System

RE-AIM: reach, effectiveness, adoption, implementation, and maintenance

SCD: sickle cell disease

SCDIC: sickle cell disease implementation consortium

SPIRIT: Standard Protocol Items for Clinical Trials

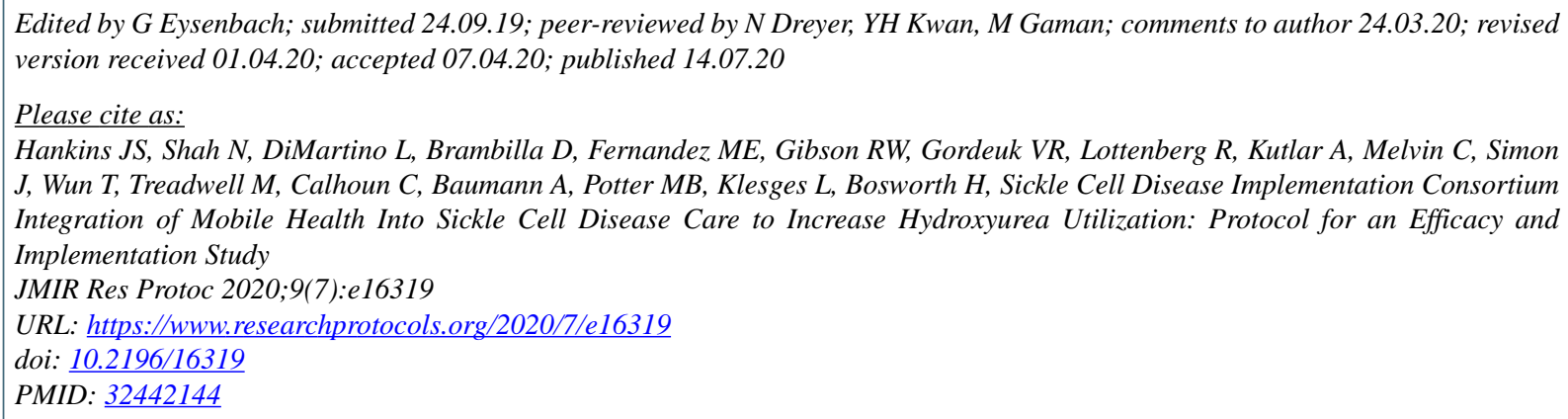

(CJane S Hankins, Nirmish Shah, Lisa DiMartino, Donald Brambilla, Maria E Fernandez, Robert W Gibson, Victor R Gordeuk, Richard Lottenberg, Abdullah Kutlar, Cathy Melvin, Jena Simon, Ted Wun, Marsha Treadwell, Cecelia Calhoun, Ana Baumann, Michael B Potter, Lisa Klesges, Hayden Bosworth, Sickle Cell Disease Implementation Consortium. Originally published in JMIR Research Protocols (http://www.researchprotocols.org), 14.07.2020. This is an open-access article distributed under the terms of the Creative Commons Attribution License (https://creativecommons.org/licenses/by/4.0/), which permits unrestricted use, distribution, and reproduction in any medium, provided the original work, first published in JMIR Research Protocols, is properly cited. The complete bibliographic information, a link to the original publication on http://www.researchprotocols.org, as well as this copyright and license information must be included. 